\title{
Optimal Consumption and Investment with Insurer Default Risk ${ }^{+}$
}

\author{
Bong-Gyu Jang*, Hyeng Keun Koo ${ }^{\dagger}$, and Seyoung Park ${ }^{\ddagger}$
}

${ }^{*}$ Department of Industrial and Management Engineering, POSTECH, Korea. Tel: +82-54-279-2372, Fax:

+82-54-279-2870, E-mail: bonggyujang@postech.ac.kr

${ }^{\dagger}$ Department of Business Administration, Ajou University, Korea. Tel: +82-31-219-2706, E-mail: koo_h@msn.com

${ }^{\ddagger}$ School of Business and Economics, Loughborough University, Epinal Way, Loughborough, Leicestershire,

UK, LE11 3TU, Tel: +44-07927494518, E-mail: S.Park@lboro.ac.uk

${ }^{+}$A primitive version of this paper titled "Default Risks of Life Annuity and the Annuity Puzzle" was presented at the 2009 China International Conference in Finance and the 2009 Co-conference in Finance of Korea. We would like to thank John Y. Campbell, Joel Peress, Laura Veldkamp, Bong Soo Lee, Mark Loewenstein, Moshe A. Milevsky, Virginia Young, Steven Kou, Min Dai, Huainan Zhao, Sojung Park and the seminar participants at the 10th International Conference on Asia-Pacific Financial Markets for helpful discussions and insightful comments. This article is a revised version of Chapter 2 of Seyoung Park's Ph.D. dissertation submitted to the Department of Industrial and Management Engineering, POSTECH. This research in the paper is supported by the National Research Foundation of Korea Grant funded by the Korean Government (NRF-2017R1A2B4006224). 


\title{
Optimal Consumption and Investment with Insurer Default Risk
}

\begin{abstract}
We solve the optimal consumption and investment problem in an incomplete market, where borrowing constraints and insurer default risk are considered jointly. We derive in closed-form the optimal consumption and investment strategies. We find two main results by quantitative analysis. As insurer default risk increases, the proportion of wealth invested in stocks could increase when wealth is small, and decrease when wealth is large. As risk aversion increases, the voluntary annuity demand could increase when insurer default risk is low, and decrease when this risk is high.
\end{abstract}

Keywords: optimal consumption, optimal investment, insurer default risk, annuity demand

JEL Classifications: C61, E21, G11 


\section{Introduction}

The financial crisis of 2008 has driven an increase in concern about risk of potentially catastrophic pension default, which causes significant decrease in pension benefits. ${ }^{1}$ This uncertainty is a result of a wide variety of global financial and demographic trends. The fiscal pressure on the public pension system is increasing because of increase in life expectancy and decrease in birthrates. The support ratio, i.e., the ratio of workers to pensioners, is also decreasing in most of the developed world. ${ }^{2}$ The fiscal deficits are expected to continue for the foreseeable future, at least, until effective legislation is enacted or benefits are changed. ${ }^{3}$ Pension plans are inevitably affected negatively by a funding deficit, so pension benefits must decrease. ${ }^{4}$

\footnotetext{
${ }^{1}$ According to the pension fund return statistics in selected OECD countries (Figure 1), corporate and public pension systems in most countries have undergone large and negative returns on their public pension funds during the recent economic crisis.

${ }^{2}$ In the U.S. the number of workers paying into the pension program was 5.1 per retiree in 1960. However, in 2007 the number decreased to 3.3. This is expected to further decrease to 2.1 by 2035. For the details, see the 2010 annual report of the board of trustees of the federal old-age and survivors insurance and federal disability insurance trust funds.

${ }^{3}$ Although some countries can access enough sovereign wealth funds which can be used to provide for retirees, many other countries have substantial political economy constraints on the size of such a fund in the long term, so their ability to fully pre-fund post-retirement financial resources can be limited.

${ }^{4} \mathrm{~A}$ major cut in pension benefits ahead took place in the U.S. on July 18, 2013, when the city of Detroit, Michigan filed for Chapter 9 bankruptcy and consequently, proposed pension benefit cuts. A deal to cut monthly pension benefits for thousands of retirees by $4.5 \%$ was unanimously endorsed by a Detroit pension board on April 16, 2014. Other examples of bankruptcy in the U.S. include: Jefferson County, Alabama, which filed for bankruptcy on November 9, 2011, and Stockton, California, which filed for Chapter 9
} 
We consider a retiree who participated in defined benefit (DB) pension plans and receives a defined life annuity that replaces a certain percentage of her last labor income. We simply capture such uncertainty in annuity income by assuming that an unexpected, large, and negative income shock occurs at a probability that follows an exponential distribution with positive intensity. Within a utility-maximizing framework, the retiree who lives finitely has a standard constant relative risk aversion utility function. The retiree encounters constant investment opportunities provided by one risk-free bond and one risky stock in the financial market.

We solve the optimal consumption and investment problem in an incomplete market, where borrowing constraints and insurer default risk are considered jointly. We derive in closed-form the optimal consumption and investment strategies. We find two main results by quantitative analysis.

- As insurer default risk increases, the proportion of wealth invested in stocks could increase when wealth is low, and decrease when wealth is high.

- As risk aversion increases, the voluntary annuity demand could increase when insurer default risk is small, and decrease when insurer default risk is large.

The decision to invest in the stock market is determined by two considerations: a precautionary savings motive that decreases investment, and a risk diversification motive that increases investment. We numerically verify the existence of a threshold level of bankruptcy on June 28, 2012. In the UK, about 70 percent of defined benefit pension schemes have been identified as deficits according to the Pension Protection Fund data. 
wealth below which the hedging demand $H$ induced by risk diversification motive dominates precautionary savings motive $P$, and above which $P$ dominates $H$. Overall, a strategy of reducing consumption and increasing savings is effective to accumulate wealth to prepare for cuts in benefits.

The annuity-income-to-wealth-ratio (non-financial-income-to-wealth-ratio) is a driving factor that underlies the investment portfolio. This ratio is inversely related to the wealth of the retiree. The annuity is a major source of income for a relatively poor retiree, so she should concern herself with diversifying insurer default risk by investing in the stock market. In contrast, the annuity is a relatively smaller major source of income for a wealthy retiree, so she has greater tolerance for insurer default risk than the poor retiree. Hence, the wealthy retiree would rather be concerned with the effects of default risk. The disparity of the income-to-wealth ratio between poor and rich is the leading cause of the differing portfolio decisions.

To our best knowledge, only two papers have studied questions related to the effects of potential benefit cuts on the behavior of retirees. Lopes and Michaelides (2007) conclude that an assumption of high risk aversion for a rare event is necessary to change the annuity demand of a retiree, but that high risk aversion itself increases the attractiveness of defaultable annuities as insurance against longevity risk. In contrast, Babbel and Merrill (2007) assert that participation in the annuity market may be low, especially when retirees are exposed to the risk that annuity providers may default. Our paper is the first to reconcile these seemingly contradictory conclusions. We show that if default risk is small, the retiree's voluntary annuity demand increases as her risk aversion increases; this inference 
is consistent with the findings of Lopes and Michaelides. We also find that if default risk is large, the annuity demand decreases with risk aversion; this inference is compatible with the findings of Babbel and Merrill. Overall, the decision to buy more or fewer annuities is influenced, to a large extent, by the way in which large insurer default risk is conceptualized and modelled.

This paper is related to a large body of strands in the literature that studies the optimal consumption and investment in the presence of nontradable income. Since the seminal paper of Yaari (1965), other researchers (e.g., Richard, 1975; Davidoff et al., 2005; Park, 2015) have shown that the optimal strategy under an uncertain lifetime and in the absence of bequest motive is to annuitize all wealth. Based on the optimal consumption and portfolio choice of Merton (1969, 1971), Milevsky and Young (2007), Bayraktar et al. (2009) have sought optimal strategies in an incomplete market, where income risk or mortality/longevity risk cannot be fully diversified away; their results have supported the conclusion that full annuitization is the optimal strategy.

Despite these theoretical predictions in complete or incomplete markets, the actual annuity market is quite thin; this status gives rise to the so-called annuity puzzle. Numerous authors have tried to resolve this puzzle. The market price of annuities is higher than their actuarially fair price, as a consequence of adverse selection of annuity buyers (Mitchell et al., 1999). A strong bequest motive of annuity buyers can generate low annuity demand (Friedman and Warshawsky, 1990; Brown, 2001; Johnson et al., 2004). Inkmann et al. (2011) thoroughly analyze the determinants of annuity demand by considering microeconomic data for the United Kingdom. Individual characteristics and measures of investor 
sentiment can have a strong influence on the demand for life annuities (Chalmers and Reuter, 2012). However, none of these studies investigate the effects of insurer default risk on a retiree's optimal consumption and investment strategies.

This paper is organized as follows. In Section 2, we describe our economic setting with forced default events of life annuity and present a retiree's optimization problem under a continuous-time setup. In Section 3, we provide analytical results regarding optimal strategies of the retiree. In Section 4, we explain main implications predicted by our model; specifically, we analyze the effects of insurer default risk on the retiree's optimal consumption and risky investment strategies and voluntary annuity demand, and measure the effects of insurer default risks by considering the certainty equivalent wealth. In Section 5 , we check the robustness of the conclusions with respect to relaxing specific assumptions about bequest motive, correlation between stock price and annuity default event, and mortality rates. In Section 6, we conclude the paper.

\section{Continuous-Time Model for Life Annuity with De- fault Risk}

\subsection{Economic Setting}

We consider the optimal consumption and portfolio selection problem of a retiree who has a standard constant relative risk aversion (CRRA) utility function:

$$
U=E\left[\int_{0}^{\tau_{M}} e^{-\beta t} \frac{c_{t}^{1-\gamma}}{1-\gamma} d t+e^{-\beta \tau_{M}} B\left(X_{\tau_{M}}\right)\right]
$$


where $E$ is the expectation taken at time $0, c_{t}$ is per-period consumption, $\tau_{M}$ is the time of the retiree's death, $B$ is a strictly increasing and concave function representing the retiree's bequest motive, $X_{\tau_{M}}$ is the retiree's wealth at her death time, $\beta>0$ is the retiree's subjective discount rate, and $\gamma>0$ is her coefficient of relative risk aversion. ${ }^{5}$ We assume that $\tau_{M}$ is distributed with intensity $\nu_{s}$ at instant $s \geq 0$ : for time $t \geq 0$,

$$
\text { Probability of }\left\{\tau_{M} \leq t\right\}=\int_{0}^{t} \nu_{s} d s \text {. }
$$

The retiree can trade securities. The securities market consists of two assets: a bond (or a risk-free asset) and a stock (or a risky asset). The bond price $B_{t}$ follows

$$
d B_{t}=r B_{t} d t
$$

where $r>0$ is the risk-free interest rate, and the stock price $S_{t}$ evolves according to the following geometric Brownian motion:

$$
d S_{t}=\mu S_{t} d t+\sigma S_{t} d W_{t}
$$

where $\mu>r$ is the expected rate of the stock return, $\sigma>0$ is the volatility of the return on the stock, and $W_{t}$ is a standard Brownian motion defined on an appropriate probability space. We assume that $r, \mu$, and $\sigma$ are constant.

The retiree receives income at a rate equal to $\epsilon$ from life annuity, which she accumulated during her pre-retirement period. We assume that sale of the annuity is prohibitively costly

\footnotetext{
${ }^{5}$ Throughout our analysis, we assume that $\gamma>1$, which is empirically plausible based on the literature (e.g., Farhi and Panageas, 2007; Dybvig and Liu, 2010).
} 
for the retiree, so she cannot reduce her annuitized income from the annuity in return for an increase in financial wealth. ${ }^{6}$

We assume that the provider of the annuity is subject to default risk. The retiree can receive a proportion $0 \leq k<1$ of the income from the annuity if the provider defaults, so she obtains income $k \epsilon$ after the default event, which can be in part an annuitized payout from a Social Security program or from the minimum subsistence provision of a public welfare program. ${ }^{7}$ Default event of the annuity provider is driven by an exogenous shock, for which the occurrence is distributed with intensity $\delta_{s} \geq 0$ at instant $s \geq 0$; for time $t \geq 0$

$$
\text { Probability of }\{\tau \leq t\}=\int_{0}^{t} \delta_{s} d s,
$$

where $\tau$ stands for the default time of the annuity provider. ${ }^{8}$

We have two sources of risk: stock market risk (a Brownian motion) and insurer (annuity provider) default risk (Poisson arrival of the default event). ${ }^{9}$ The market risk is

\footnotetext{
${ }^{6}$ In the presence of substantial transaction costs, no trading is typically optimal (Constantinides, 1986; Liu and Loewenstein, 2002; Jang et al., 2007).

${ }^{7}$ The provision of minimum subsistence for the incomeless retiree supported by the government makes sense in that it could turn out to be effective in building aggregate spending and smoothing consumption over a lifetime.

${ }^{8}$ We model the default event as a jump process. Mortality, disability, retirement, unemployment, and many other events that happen at an uncertain time have been considered by such jump process (Merton, 1971; Richard, 1975; Viceira, 2001). In this paper, the insurer's default event also occurs at an uncertain time, so that the default time $\tau$ evolving by an exponential distribution can appropriately represent this uncertainty.

${ }^{9}$ Mortality also can be regarded as another source of risk in the presence of bequest motive, which will
} 
diversifiable by controlling the investment in the stock, whereas the default risk is unhedgeable and cannot be fully diversified away in the market. In this sense, we assume that no financial vehicle (securities, financial contracts, or insurance contracts) is available to hedge against the annuity provider's default risk. Accordingly, the financial market including the securities market and the insurance market is essentially incomplete.

\subsection{The Retiree's Optimization Problem with Insurer Default Risk}

We specify the retiree's optimization problem in the presence of insurer default risk. After a default of the annuity provider, we assume that the income from annuity is recovered with the rate of $k(0 \leq k<1)$. We assume for the moment that $\nu_{s}$ and $\delta_{s}$ are constant, the insurer default risk is independent of the stock market risk, and there is no bequest motive

for simplicity of exposition, i.e., $B\left(X_{\tau_{M}}\right)=0$. We will relax this assumption in Section 5 . Then the objective function takes the following form:

$$
U=E\left[\int_{0}^{\tau_{M}} e^{-\beta t} \frac{c_{t}^{1-\gamma}}{1-\gamma} d t\right]=E\left[\int_{0}^{\infty} e^{-(\beta+\nu) t} \frac{c_{t}^{1-\gamma}}{1-\gamma} d t\right]
$$

Thus, the utility function is equal to that of an infinitely-lived person with her subjective discount rate being increased by the mortality rate $\nu$.

The retiree's problem with initial endowment $x$ before the default event is to maximize her CRRA lifetime utility (1) by controlling per-period consumption $c$ and risky investment be further investigated in our robustness section. 
$\pi$. The problem leads to the following value function:

$$
V(x) \equiv \max _{(c, \pi)} E\left[\int_{0}^{\infty} e^{-(\beta+\nu+\delta) t}\left(\frac{c_{t}^{1-\gamma}}{1-\gamma}+\delta K \frac{\left(X_{t}+k \epsilon / r\right)^{1-\gamma}}{1-\gamma}\right) d t\right],
$$

where $K=(1 / A)^{\gamma}$, and $A=\frac{\gamma-1}{\gamma}\left(r+\frac{\theta^{2}}{2 \gamma}\right)+\frac{\beta+\nu}{\gamma}$. In the right-hand side, $\delta K \frac{\left(X_{t}+k \epsilon / r\right)^{1-\gamma}}{1-\gamma}$ captures the retiree's utility value after the default event, i.e., the term is equal to the product of the default intensity $\delta$ and the maximized value of her utility after the rate of income from annuity is reduced to $k \epsilon^{10}$

The last term in the right-hand side of (2) includes the default intensity $\delta$. For the limiting case of $\delta=0$, the retiree is not exposed to default risk, so she maximizes a function of intermediate consumption (e.g., Merton, 1969, 1971). For the opposite extreme where $\delta=+\infty$, the retiree's problem is also trivial because the insurer's default is immediate and the rate of income is $k \epsilon$ forever. In this case the problem reduces to the classical optimal consumption and portfolio choice problem (e.g., Merton, 1969, 1971). Within the range $0<\delta<+\infty$ of plausible values, equation (2) shows that the insurer's default risk leads to a new interesting problem in which the retiree maximizes not only her consumption but also intermediate wealth at the time of the insurer's default.

The retiree who invests her savings in riskless and risky assets accumulates her wealth according to the following dynamics:

$$
d X_{t}= \begin{cases}\left(r X_{t}-c_{t}+\epsilon\right) d t+\pi_{t} \sigma\left(d W_{t}+\theta d t\right), & 0 \leq t<\tau \wedge \tau_{M}, \\ \left(r X_{t}-c_{t}+k \epsilon\right) d t+\pi_{t} \sigma\left(d W_{t}+\theta d t\right), & \tau \wedge \tau_{M} \leq t \leq \tau_{M},\end{cases}
$$

where $\pi$ is the dollar amount invested in the stock, $\theta=(\mu-r) / \sigma$ is the Sharpe ratio. The retiree accumulates wealth at the rate $(r X-c+\epsilon)$ before the insurer defaults, and at the

\footnotetext{
${ }^{10}$ For a detailed derivation of equation (2), we refer to Section 1 in Online Appendix.
} 
rate $(r X-c+k \epsilon)$ after the default, if we do not account for her risk taking in the stock market.

A wealth (or borrowing) constraint precludes an individual from using the full capitalized value of future income and arises due to market frictions such as informational asymmetry, agency conflicts, and limited enforcement (Farhi and Panageas, 2007; Dybvig and Liu, 2010, Jang et al., 2013). The insurer default risk is a source of market friction consistent with such a constraint. We impose the nonnegative wealth constraint (or the borrowing constraint)

$$
X_{t} \geq 0, \quad 0 \leq t<\tau,
$$

which implies that the retiree cannot borrow against her future annuity income.

After the insurer defaults, we assume that the retiree could borrow up to the present value of the lowest possible after-default income $k \epsilon$, discounted by risk-free interest rate $r$. Specifically,

$$
X_{t} \geq-\frac{k \epsilon}{r}, \quad t \geq \tau
$$

\section{Optimal Consumption and Investment Strategies}

The task of solving financial problems constructed in an incomplete market is an extremely complex one. Because of the non-uniqueness of an equivalent martingale measure, a closed-form solution of the problems cannot be found. To solve the optimal consumption and portfolio choice problem in such an incomplete market, we use a new convex-duality method (Bensoussan et al., 2016). We develop a dynamic programming approach by using 
a modified convex-dual function $G$ of the original value function $V$. If we set

$$
\lambda(x) \equiv V^{\prime}(x)
$$

and

$$
G(\lambda(x)) \equiv x+\frac{\epsilon}{r}
$$

then the following relations hold:

$$
\begin{aligned}
& G^{\prime}(\lambda(x)) \lambda^{\prime}(x)=1, \\
& G^{\prime \prime}(\lambda(x)) \lambda^{\prime}(x)^{2}+G^{\prime}(\lambda(x)) \lambda^{\prime \prime}(x)=0,
\end{aligned}
$$

for $0<\lambda<\bar{\lambda}$, where $\bar{\lambda}$ is a free boundary to be determined by the nonnegative wealth constraint (3).

Next, we derive explicitly the retiree's optimal consumption and investment strategies and discuss their properties. ${ }^{11}$

Theorem 3.1 We define $P \equiv$ insurer-default-risk-induced precautionary savings and its first term P1 and its second terms P2 as:

$$
\begin{aligned}
P & \equiv P 1+P 2 \\
& =\underbrace{\frac{2 \delta K\left(\alpha_{\delta}-1\right)}{\theta^{2}\left(\alpha_{\delta}-\alpha_{\delta}^{*}\right)(1-\gamma)} \lambda^{*}(x)^{-\alpha_{\delta}} \int_{0}^{\lambda^{*}(x)} \mu^{\alpha_{\delta}-2}\left(G(\mu)-\frac{\epsilon}{r}+\frac{k \epsilon}{r}\right)^{1-\gamma} d \mu}_{\text {first term }} \\
& +\underbrace{\frac{2 \delta K\left(\alpha_{\delta}^{*}-1\right)}{\theta^{2}\left(\alpha_{\delta}-\alpha_{\delta}^{*}\right)(1-\gamma)} \lambda^{*}(x)^{-\alpha_{\delta}^{*}} \int_{\lambda^{*}(x)}^{\bar{\lambda}} \mu^{\alpha_{\delta}^{*}-2}\left(G(\mu)-\frac{\epsilon}{r}+\frac{k \epsilon}{r}\right)^{1-\gamma} d \mu}_{\text {second term }},
\end{aligned}
$$

\footnotetext{
${ }^{11}$ In Online Appendix, the details of deriving optimal strategies with insurer default risk are provided.
} 
Then the retiree's optimal consumption $c^{*}$ and investment $\pi^{*}$ in the risky asset are derived as

$$
\begin{aligned}
& c_{t}^{*}=\left(A+\frac{\delta}{\gamma}\right)\left[\left(x+\frac{\epsilon}{r}\right)-B^{*}(\bar{\lambda} ; \delta) \lambda^{*}(x)^{-\alpha_{\delta}^{*}}-P\right], \\
& \pi_{t}^{*}=\frac{\theta}{\gamma \sigma}\left[\left(x+\frac{\epsilon}{r}\right)+\left(\alpha_{\delta}^{*}-\frac{1}{\gamma}\right) \gamma \frac{\theta}{\sigma} B^{*}(\bar{\lambda} ; \delta) \lambda^{*}(x)^{-\alpha_{\delta}^{*}}\right. \\
&-\frac{2 \gamma^{2}}{\theta^{2}(1-\gamma)} \delta K \frac{\left(x+\frac{k \epsilon}{r}\right)^{1-\gamma}}{1-\gamma} /\left\{\frac{\left(c_{t}^{*}\right)^{1-\gamma}}{1-\gamma}-c_{t}^{*} V^{\prime}(x)\right\} c_{t}^{*} \\
&\left.+\left(\alpha_{\delta}-\frac{1}{\gamma}\right) \gamma \times P 1+\left(\alpha_{\delta}^{*}-\frac{1}{\gamma}\right) \gamma \times P 2\right],
\end{aligned}
$$

where $B(\bar{\lambda} ; \delta)$ is a constant to be determined according to the value-matching and smoothpasting conditions. The two constants $\alpha_{\delta}>1$ and $-1<\alpha_{\delta}^{*}<0$ are the roots of the following characteristic equation:

$$
F(\alpha ; \delta)=-\frac{1}{2} \theta^{2} \alpha(\alpha-1)+\alpha(\beta+\nu+\delta-r)+r=0
$$

Proof. See online Appendix.

\section{Optimal Consumption Strategy with Insurer Default Risk}

When $\delta=0$, i.e., default risk is zero, optimal consumption given by equation (4) is equal to the one obtained from the classical problem in the presence of the nonnegative wealth constraint (Merton 1969, 1971):

$$
c_{t}=A\left\{\left(x+\frac{\epsilon}{r}\right)-B(\bar{\lambda} ; \delta=0) \lambda^{*}(x)^{-\alpha_{0}^{*}}\right\} .
$$

Most importantly, the effects of default risk on optimal consumption are revealed by the extra term of $P=$ insurer-default-risk-induced precautionary savings in the right-hand side 
of equation (4). The precautionary savings motive against uninsurable income risk plays a central and unifying role in the current analysis of buffer-stock savings behaviors (Wang et al., 2016). An important argument related to the precautionary savings motive is that the borrowing-constrained retiree facing insurer default risk is likely to reduce consumption to increase additional reserves in a precautionary way or to finance current consumption by using her savings. More specifically, insurer-default-risk-induced precautionary savings $(P)$ are divided into two terms: the first term of precautionary savings $(P 1)$ can be thought of as a resource that is used to finance consumption and thus, results in an increase in consumption; the second term $(P 2)$ can be thought of as precautionary savings that results in a decrease in consumption. In particular, the incentives to increase precautionary savings to finance consumption get stronger as the retiree's wealth gets smaller and at the extreme case of wealth close to zero,

$$
P \rightarrow \frac{2 \delta K\left(\alpha_{\delta}-1\right) \bar{\lambda}^{-\alpha_{\delta}}}{\theta^{2}\left(\alpha_{\delta}-\alpha_{\delta}^{*}\right)(1-\gamma)} \int_{0}^{\bar{\lambda}} \mu^{\alpha_{\delta}-2}\left(G(\mu)-\frac{\epsilon}{r}+\frac{k \epsilon}{r}\right)^{1-\gamma} d \mu<0 \quad \text { as } \quad x \rightarrow 0
$$

Naturally, the incentives to finance consumption become weaker as the retiree accumulates wealth, and in the extreme case of sufficiently large wealth,

$$
P \rightarrow 0 \text { as } x \rightarrow \infty
$$

which implies that for the wealthy retiree, consumption can be sustained comfortably even in the event of insurer default.

\section{Optimal Investment Strategy with Insurer Default Risk}


Setting $\delta=0$ in the right-hand side of (5), we can derive the optimal investment in the absence of default risk:

$$
\pi_{t}=\frac{\theta}{\gamma \sigma}\left(x+\frac{\epsilon}{r}\right)+\left(\alpha_{0}^{*}-\frac{1}{\gamma}\right) \frac{\theta}{\sigma} B(\bar{\lambda} ; \delta=0) \lambda^{*}(x)^{-\alpha_{0}^{*}}
$$

The nonnegative wealth constraint tends to decrease investment in a risky asset; this trend is represented by the second term of the right-hand side of (7). The intuition behind this is very simple: the borrowing-constrained retiree is inclined to decrease risky exposure and increase riskless asset holdings to avoid binding borrowing constraints in the future; this trend gets stronger as the retiree's wealth gets smaller.

More interestingly, the effects of default risk on risky investment are not always obvious, but rather are non-monotonic in the magnitude of the risk, depending on levels of financial wealth. We emphasize that the retiree can partially hedge against uninsurable insurer default risk by investing in the stock, and this hedging demand for the stock can increase as the insurer default risk increases, especially when retiree's wealth is small. As a result, endogenous adjustments of risky investment can have an effect on future consumption. Indeed, the third term of the right-hand side of (5) represents such hedging demand to reserve resources available for future consumption in the face of insurer default risk, and in turn results in an increase in stock investment to take advantage of the positive risk premium and thus to accumulate wealth faster. More precisely, the third term

$$
\delta K \frac{\left(x+\frac{k \epsilon}{r}\right)^{1-\gamma}}{1-\gamma} /\left\{\frac{\left(c_{t}^{*}\right)^{1-\gamma}}{1-\gamma}-c_{t}^{*} V^{\prime}(x)\right\}
$$

is the ratio of the retiree's utility value after the default event to the utility value from 
optimal consumption. ${ }^{12}$ Increase in risk associated with the income stream from annuities (or increase in insurer default intensity $\delta$ ) increases the hedging demand which provides motive to diversify and to accumulate wealth faster. In particular, the hedging demand against insurer default risk increases in importance as wealth approaches zero:

$$
\begin{aligned}
-\frac{2 \gamma^{2}}{\theta^{2}(1-\gamma)} & \delta K \frac{\left(x+\frac{k \epsilon}{r}\right)^{1-\gamma}}{1-\gamma} /\left\{\frac{\left(c_{t}^{*}\right)^{1-\gamma}}{1-\gamma}-c_{t}^{*} V^{\prime}(x)\right\} c_{t}^{*} \\
& \rightarrow-\frac{2 \gamma^{2}}{\theta^{2}(1-\gamma)} \delta K \frac{\left(\frac{k \epsilon}{r}\right)^{1-\gamma}}{1-\gamma} /\left\{\frac{\gamma}{1-\gamma} \bar{\lambda}^{1-1 / \gamma}\right\} \bar{\lambda}^{-1 / \gamma} \text { as } x \rightarrow 0 .
\end{aligned}
$$

The precautionary savings motive against insurer default risk is also a crucial element when the retiree invests in the risky asset. Our optimal investment rule (5) in the risky asset shows analytically that the amount of investment decreases by proportions of insurerdefault-risk-induced precautionary savings ( $P 1$ and $P 2)$. Concretely, the proportion $\left(\alpha_{\delta}-\right.$ $\left.\frac{1}{\gamma}\right) \gamma$ of the first term of insurer-default-risk-induced precautionary savings $(P 1)$ and the proportion $\left(\alpha_{\delta}^{*}-\frac{1}{\gamma}\right) \gamma$ of the second term of insurer-default-risk-induced precautionary savings $(P 2)$ are saved in the form of the riskless asset. This precautionary savings motive against insurer default risk also increases in importance as wealth approaches zero:

$$
\begin{aligned}
& \left(\alpha_{\delta}-\frac{1}{\gamma}\right) \gamma \times P 1+\left(\alpha_{\delta}^{*}-\frac{1}{\gamma}\right) \gamma \times P 2 \\
& \rightarrow\left(\alpha_{\delta}-\frac{1}{\gamma}\right) \gamma \times \frac{2 \delta K\left(\alpha_{\delta}-1\right)}{\theta^{2}\left(\alpha_{\delta}-\alpha_{\delta}^{*}\right)(1-\gamma)} \bar{\lambda}^{-\alpha_{\delta}} \int_{0}^{\bar{\lambda}} \mu^{\alpha_{\delta}-2}\left(G(\mu)-\frac{\epsilon}{r}+\frac{k \epsilon}{r}\right)^{1-\gamma} d \mu \text { as } x \rightarrow 0 .
\end{aligned}
$$

The combined effects indicate that the retiree's level of wealth affects her optimal investment in the stock in the presence of insurer default risk. An important observation

\footnotetext{
${ }^{12}$ The utility value from optimal consumption is given by
}

$$
\left\{\frac{\left(c_{t}^{*}\right)^{1-\gamma}}{1-\gamma}-c_{t}^{*} V^{\prime}(x)\right\}=\frac{\gamma}{1-\gamma} \lambda^{*}(x)^{-1 / \gamma}
$$

which is from the Hamilton-Jacobi-Bellman equation given in the online Appendix. 
here is the possibility of a threshold level of wealth below which the hedging demand $H$ that increases equity demand dominates the precautionary savings motive $P$ that decreases equity demand, and above which $P$ dominates $H$, which will be verified in our quantitative analysis in the next section.

\section{Numerical Illustrations}

In this section, we obtain numerical solutions and present graphical illustrations to provide details to the discussion regarding optimal strategies. For this purpose, we use an iterative numerical procedure (online Appendix). We calibrate asset returns following the important life-cycle models (Cocco et al., 2005; Farhi and Panageas, 2007; Dybvig and Liu, 2010). We set the equity premium to $6 \%$, which is the historical average value. We set the bond return to $2 \%$, because the recent interest rates are very low, and set the stock volatility to $20 \%$. We set the annual rate of annuity payments to be 1 , i.e., $\epsilon=1$, and the retiree's expected lifetime to be 20 years, or equivalently, $\nu=0.05$. We set the subjective discount factor $\beta=0.04$ (Cocco et al., 2005). We also assume that the relative risk aversion coefficient $\gamma=4^{13}$

Default intensity $\delta$ is calibrated based on Moody's (2012) historical data of average cumulative issuer-weighted global default rates by rating categories for the time period

\footnotetext{
${ }^{13}$ The portfolio choice literature regarding the life-cycle model uses the standard and moderate relative risk aversion coefficient. For instance, Farhi and Panageas (2007) consider a range of values from 2 to 4 for this coefficient, and Dybvig and Liu (2010) set $\gamma=3$ for the baseline parameter value. Cocco et al. (2005) use the upper bound for risk aversion of $\gamma=10$.
} 
from 1983 to 2011. Similarly, Lopes and Michaelides (2007) and Babbel and Merrill (2007) use corporate debt ratings by a credit rating agent like Moody's to estimate default probability of life annuities. The statistics related to federal, state, municipal and other local governments are not available in sufficiently credible quantities, so Moody's historical data on corporate defaults is used to calibrate the insurer default intensity $\delta$. A deterioration of corporate credit rating constitutes major risks to life insurers (Impavido and Tower, 2009). We select four categories, $A a a, A a, A$, and $B$, to calibrate the default intensity. It is calibrated as follows: 0.0001 for Aaa, 0.0012 for $A a, 0.0030$ for $A, 0.0526$ for $B$.

In the U.S. the NOLHGA and its state government members provide retired people with minimum benefit guarantees by recovering parts of remaining benefits after default of annuity providers. The coverage limit for most of states is $\$ 100,000$ in withdrawal and cash values for annuities. As a result, the rest of the coverage exceeding the coverage limit is recovered according to the liquidation ratio, which is the amount of assets available in the insolvent estate. Therefore, we regard the recovery rate as the recovery amount of the excess claim. We take three values of the recovery rate $k$ of the excess claim to be $30 \%$, $40 \%$, and $50 \% \cdot{ }^{14}$

\subsection{Optimal Consumption and Investment in the Risky Asset}

Figure 2 displays the retiree's optimal consumption ratio and investment ratio in the risky asset as a function of initial wealth for different levels of default risk when the recovery rate $k$ equals to 0.3 , i.e., the recovery amount is $30 \%$ of the excess claim. As expected,

\footnotetext{
${ }^{14}$ Babbel and Merrill (2007) consider a range of values from $0 \%$ to $25 \%$ for the recovery rate.
} 
the optimal consumption ratio decreases as wealth or default risk increases. These findings are consistent with the standard life-cycle models (Cocco et al., 2005; Polkovnichenko, 2007) in that the presence of default risk of life annuity, i.e., income risk constitutes the precautionary savings motive.

\section{[Insert Figure 2 here.]}

An important implication of this paper is that the effects of the insurer's default risk on portfolio policies vary with a change in the retiree's wealth. The portfolio share in the risky asset increases as default risk increases when the retiree's wealth is small, whereas the portfolio share decreases with default risk when the retiree's wealth is large. In summary, a threshold level of wealth exists, below which the portfolio share increases as default risk increases and above which it decreases as default risk increases.

An increase in default risk of a life annuity has two possibly counteracting effects on the retiree's optimal portfolio choice. First, the increase results in an increase in background risk, ${ }^{15}$ so precaution will encourage the retiree to become increasingly conservative; i.e., as the riskinesss of the retiree's income increases, the investment in the risky asset decreases. Second, a defaultable annuity also is a risky asset, so the retiree has no choice but to resort to higher-yielding alternatives by aggressive investment in the stock market. The prices of high-risk investments are adjusted to increase their expected returns, and a rise in default risk can be partially spanned by investing in the stock market in a search for a

\footnotetext{
${ }^{15}$ The background risk is an undiversifiable risk that affects an economic agent's portfolio choice. Typical examples of background risk are income risk and risk of house ownership (Bodie et al., 1992; Heaton and Lucas, 1997; Koo, 1998).
} 
positive risk premium, which is ultimately induced by risk diversification purposes. As a result, the share of wealth in the risky asset can increase with an increase in default risk if the diversification motive dominates the precautionary savings motive; whereas the share or wealth invested in the risky asset can decrease with an increase in default risk if the diversification motive is dominated by the precautionary savings motive.

The annuity-income-to-wealth-ratio (non-financial-income-to-wealth-ratio) is inversely related to the retiree's wealth. The annuity is a major staple of the relatively poor retiree and she should concern herself with diversifying the default risk by investing in the stock market. In contrast, the annuity is a relatively smaller staple of the rich retiree, so she has greater tolerance for risk than the poor retiree, and therefore is primarily concerned with the effects of background risk itself. The disparity of the income-to-wealth ratio between poor and rich is the root cause of their different portfolio decisions.

\section{Changes in Recovery Rate}

Optimal consumption and investment in the risky asset depend on recovery rates and default intensities (Table 1). As recovery rate of the life annuity increases or as the annuity provider's credit rating increases, the retiree increases her consumption. For instance, due to the precarious financial condition of the annuity provider, the optimal consumption ratio decreases from $18.88 \%$ to $17.80 \%$ if the credit rating decreases from $A$ to $B$, for the case where $k=0.5$ and $x=10$.

Interestingly, the default risk differently affects the retiree's optimal portfolio choice, and the difference is affected by the recovery rate. This also is a manifestation of the two 
opposing effects of default risk that bring to the portfolio share. The retiree can be likely to become either increasingly aggressive or increasingly conservative when investing in the stock market in the event of incoming insurer default. Suppose a sharp decline in the credit rating of the annuity provider from $A$ to $B$ and a moderate amount $x=10$ of initial wealth. If the retiree can recover $30 \%$ of her annuity income if her insurer defaults, her optimal risky investment should decrease from $111.37 \%$ to $107.94 \%$. However, if she can recover $50 \%$ of her annuity income if the insurer defaults, her optimal risky investment should increase from $110.82 \%$ to $124.36 \%$. The precautionary savings motive that decreases investment and the risk diversification motive that increases investment are somewhat counterbalanced by the recovery rate. ${ }^{16}$

\section{[Insert Table 1 here.]}

\section{Changes in Risk Aversion}

Changes in risk aversion affect the optimal strategy (Figure 3). For simplicity, we assume that the retiree has a small amount of wealth, for instance her initial endowment is 5. Reduced risk aversion leads the retiree to increase her consumption ratio and increase

\footnotetext{
${ }^{16}$ These two opposing effects on investment also have an influence on consumption. In Table 1 , for the case where $k=0.5$ and $x=1$, it seems that the consumption ratio increases with increase in default risk $\delta$, contrary to another case where $k=0.3$ and $k=0.4$ for the same wealth level $x=1$. Given the dominance of the risk diversification motive over the precautionary savings motive, such an increase in consumption could be achieved with the help of both a high recovery rate and an increased compensation for investment in the stock. This result might imply that the retiree can partially hedge against the default risk by investing in the risky asset and thus in some cases, increase consumption as default risk increases.
} 
the investment ratio in the risky asset, irrespective of the extent of insurer default risk. However, the effects of insurer default risk crucially depend on both the extent of the default risk and the degree of risk aversion. For retirees with low risk aversion, the default risk is most likely to be negligible, so that their optimal strategies become increasingly dependent on the degree of risk aversion, ceteris paribus, unless the default event is soon to come, for example if the credit rating of the annuity provider is $B$. In contrast, retirees with high risk aversion perceives the default risk intensely, so their optimal behaviors tend to be independent of the degree of risk aversion, even for a moderate default risk. Summarizing, the default risk of life annuities has a large impact on the retiree's optimal consumption and investment decisions, especially for the highly risk-averse retiree.

\section{[Insert Figure 3 here.]}

\section{Changes in Investment Opportunity}

The investment opportunity affects the retiree's optimal choices of consumption (Table 2) and investment (Table 3). As expected, the retiree is willing to increase consumption and increase investment in the risky asset if the investment opportunity improves, or equivalently, if the expected return on the risky asset is high or the volatility of the return is low, or both.

\section{[Insert Table 2 and 3 here.]}

The retiree might drastically reduce her consumption ratio in the face of high default risk (Table 2). For example, when the retiree has initial wealth 10, and the credit rating 
of the insurance company changes from $A$ to $B$, the consumption declines from $17.53 \%$ to $17.05 \%$ when expected rate of stock return is $7 \%$, but from $13.46 \%$ to $12.83 \%$ when the expected rate of stock return is $6 \%$. Reduction in consumption due to an increase in default risk increases in significance as the investment opportunity worsens.

For a fixed amount of wealth, the retiree's investment ratio can increase or decrease with insurer default risk, depending on whether the market is up or down (Table 3). For instance, when the credit rating of the annuity provider declines from $A$ to $B$, the retiree with initial wealth of 10 increases her investment ratio in the risky asset from $73.44 \%$ to $90.64 \%$ if volatility of the risky asset is $21 \%$, but decreases her investment ratio from $67.32 \%$ to $59.98 \%$ if the volatility is $22 \%$. When the market is increasing, stock investment becomes attractive because the resulting positive risk premium improves the retiree's wealth when she diversifies the default risk. However, when the market is decreasing, the effectiveness of hedging with the stock investment is also reduced, so the default risk can mean that the retiree's optimal strategy is to increase her savings.

\subsection{Annuity Demand with Insurer Default Risk}

In this section, we calculate the actuarially fair price and the retiree's implicit value of life annuity, and compare these two values. The implicit value of life annuity is the marginal rate of substitution between annuity holdings and financial wealth (Koo, 1998), so it is the retiree's subjectively perceived value of her annuity holdings, i.e., her reservation price of

an annuity when she is offered to purchase or sell a small amount of it. This implicit value 
is a proxy for the retiree's annuity demand; a higher value than the market price implies that the retiree would be willing to buy it and a lower value than the market price implies that she would be willing to sell it if she were given an opportunity to do so.

The actuarially fair price serves as a benchmark to set the market price by the annuity provider (Mitchell et al., 1999). The actuarially fair price can be calculated as

$$
E\left[\int_{0}^{\tau \wedge \tau_{M}} \epsilon e^{-r t} d t\right]=\frac{\epsilon}{r+\nu+\delta}
$$

and, for comparison purposes, we define the benchmark price as the actuarially fair price without the default risk (i.e., $\delta=0$ ). We introduce the definition of the implicit value of life annuity.

Definition 4.1 Let us denote the value function defined in (2) by $V(x, \epsilon, \delta)$, which is a function of initial wealth $x$, rate $\epsilon$ of income from the annuity, and default intensity $\delta$. Then the implicit value of life annuity is defined by

$$
\frac{\partial V(x, \epsilon, \delta)}{\partial \epsilon} / \frac{\partial V(x, \epsilon, \delta)}{\partial x}
$$

The implicit value of life annuity increases as the amount of wealth increases, regardless of insurer default risk (Figure 4). This trend implies that the retiree is interested in taking an increasing share of the life annuity as her wealth increases. Inkmann et al. (2011) make a similar finding; this agreement suggests that annuities are attractive to rich retirees. However, if insurer default risk is high (i.e., credit rating $B$ ), the implicit value can decrease below the benchmark price. ${ }^{17}$ Accordingly, an imminent insurer default could help explain

\footnotetext{
${ }^{17}$ In this aspect, when studying annuity demand, the implicit value corresponding to the high default rate (i.e., credit rating $B$ ) would be another benchmark, in addition to the actuarially fair price.
} 
the low level of annuitization.

\section{[Insert Figure 4 here.]}

\section{Changes in Recovery Rate}

The implicit value of life annuity varies with the recovery rate (Figure 5). The level of recovery rate does not appear to affect the implicit value if the insurance provider has a good credit rating. However, when incoming insurer default is possible, such as a credit rating of $B$, then an increase in the recovery rate looks likely to be able to increase the implicit value, and thereby reduce the demand for selling or refunding life annuities.

\section{[Insert Figure 5 here.]}

\section{Changes in Risk Aversion}

Lopes and Michaelides (2007) arguably state that the low annuity take-up in the actual annuity market cannot be explained by the possibility of rare events, like default of the annuity provider. The retiree must have high risk aversion before a rare event can change her annuity demand, but high risk aversion on its own drives the retiree to purchase additional annuities as insurance against mortality risk. In contrast, Babbel and Merrill (2007) demonstrate that participation in the annuity market could be reduced considerably as retirees encounter default risk of annuity providers. We show that if default risk is small, the retiree's voluntary annuity demand increases as her risk aversion increases; this result is consistent with the finding of Lopes and Michaelides. We also identify that if default risk is large, the annuity demand decreases as risk aversion increases; this result is compatible 
with the finding of Babbel and Merrill. Overall, the choice of quantity of annuities to buy is strongly influenced by the way in which large insurer default risk is conceptualized and modeled.

Increased risk aversion drives retirees to increase the amounts of annuities that they purchase when they are faced with moderate insurer default risk (e.g., case Aaa, Figure 6); this result is consistent with Lopes and Michaelides (2007). However, this result can be reversed when insurance providers are on the brink of default (e.g., case $B$, Figure 6). In this case, the voluntary annuity demand decreases as risk aversion increases, and this conclusion is consistent with Babbel and Merrill (2007).

The function of a life annuity provides an intuitive explanation for why the relation between the retiree's voluntary annuity demand and her risk aversion varies with the extent of insurer default risk. Traditionally, a life annuity has been regarded as riskless bond holdings; as a result, the retiree's inclination to invest in the annuity market increases as her risk aversion increases; the purpose is to hedge against the risk that the retiree will outlive her financial resources. However, defaultable annuities are no longer effective as hedging tools against this longevity risk. Rather, defaultable annuities themselves appear to be implicitly risky, like those risky equity holdings. Accordingly, the willingness to reduce investment in the annuity market increases as the retiree's risk aversion increases.

\section{[Insert Figure 6 here.]}

\section{Changes in Investment Opportunity}

The implicit value of the life annuity changes with investment opportunity (Table 4). 
When the default risk is low, the implicit value rises if the investment opportunity degrades, and subsequently, life annuity becomes increasingly attractive to retirees as the stock market tends to decline; this conclusion is consistent with Chalmers and Reuter (2012) and Previtero (2014). However, an increase in insurer default risk (e.g., for the credit ratings $A a, A$, and $B)$ can cause the opposite result: the attractiveness of life annuity to retirees decreases even with increased probability that market will decline; this conclusion is contrary to common intuition. The counterintuitive trend occurs because defaultable annuities are no longer safe assets and retirees should concern themselves so much with focusing on the negative effect of imminent insurer default; consequently, they are willing to reduce their investment in the annuity market, to avoid worrying about additional sources of risk.

[Insert Table 4 here.]

\subsection{Certainty Equivalent Wealth Gain from Considering Insurer Default Risk}

Now, we analyze the economic significance of clearly incorporating insurer default risk. As an example, suppose a retiree has no insurer default risk, i.e., the life annuity is free of default risk. After taking this consideration, another retiree who is faced with insurer default risk is likely to pay additional money to make her life annuity default-free. We compute the certainty wealth gain (CEWG) as the dollar amount of initial endowment of the retiree as a result of correctly considering the insurer default risk. The CEWG is a kind of compensation for the retiree in return for bearing the default risk of annuity provider. We 
discuss the various properties of CEWG under changes in fundamental parameter values.

Definition $4.2 \Delta(x)$ is called the certainty equivalent wealth gain at wealth level $x$ if it satisfies

$$
V(x-\Delta(x), \epsilon, 0)=V(x, \epsilon, \delta) .
$$

CEWG is a decreasing function of the retiree's initial wealth (Figure 7), because the retiree's ability to manage insurer default risk is increased as her wealth increases; i.e., wealth itself can be used as a buffer to absorb the default risk. ${ }^{18}$ Moreover, the CEWG increases as default risk increases. Retirees should be so fixated on exposing the current displeasing traits of their defaultable life annuities, as a result, they are entitled to this large compensation. This finding strongly supports the economic importance of considering the insurer default risk when the retiree is consuming and investing in the stock and annuity markets.

\section{[Insert Figure 7 here.]}

\section{Changes in Recovery Rate}

CEWG is sensitive to changes in the recovery rate (Figure 8). As expected, as the retiree's recovery rate after insurer default increases, her entitlement to compensation decreases.

\footnotetext{
${ }^{18}$ The CEWG converges to zero as wealth approaches infinity. The retiree who is exposed to insurer default risk cannot expect for sure how much or how long exactly benefits will be provided from her defaultable life annuities over her remaining lifetime. No retiree can have zero CEWG unless her amount of wealth is infinite.
} 


\section{[Insert Figure 8 here.]}

\section{Changes in Risk Aversion}

The CEWG increases as the retiree's risk aversion increases (Figure 9). Obviously, an increase in risk aversion is likely to increase the pressure on the retiree to manage insurer default risk. An increase in insurer default risk further decreases disposable annuity income; this change results in increased compensation to mitigate the insurer default risk (e.g., $B$ vs. $A a a, A a$, or $A)$.

\section{[Insert Figure 9 here.]}

\section{Changes in Investment Opportunity}

CEWG is sensitive to changes in expected stock return $\mu$ and stock volatility $\sigma$ (Table 5). When the market is low, i.e., when $\mu$ is low, or $\sigma$ is high, or both, retirees who are free of insurer default risk achieve substantial CEWGs. The gain resulting from behavior that correctly takes into account the default risk of life annuities can be an order of magnitude, especially during a decreasing stock market.

[Insert Table 5 here.]

\section{General Case and Robustness}

In this section, we will show that our main results do not change by the simplifying assumptions that the retiree has no bequest motive, that the correlation between the risky 
asset price and the default event of the insurance provide is zero, and that mortality rate $\nu$ is constant.

The bequest motive is that the retired person would like to bequeath part of her wealth to heirs at death. This can further decrease the annuity take-up by the retiree. This conclusion has been established by many other studies (e.g., Friedman and Warshawsky, 1990; Brown, 2001; Johnson et al., 2004). The addition of the bequest motive only reinforced our conclusion.

Next, we consider a non-zero correlation between the risky asset price and default intensity, and examine the effect of this correlation on the voluntary annuity demand (or equivalently, the implicit value of life annuity). Throughout this section, we assume that the risky asset considered in our model is a well-diversified portfolio such as a worldwide stock index, so the price fluctuation of the risky asset depends only on a systematic risk factor. To impose a non-zero correlation between the systematic risk factor and the default risk of annuity provider, we use a stochastic process $\delta_{s}$ (Blanchet-Scalliet et al., 2008) as a time-varying default intensity; ${ }^{19}$ for time $t \geq 0$,

$$
\text { Probability of }\{\tau \leq t\}=\int_{0}^{t} \delta_{s} d s
$$

satisfying, for time $t \geq 0$,

$$
d \delta_{s}=a \delta_{s} d s+b \delta_{s} d W_{s}^{*}, \quad \delta_{0}=\delta>0, a<0, b>0,
$$

\footnotetext{
${ }^{19}$ The process, $\delta_{s}$, of Blanchet-Scalliet et al. (2008) might not satisfy $\int_{0}^{\infty} \delta_{s} d s \leq 1$. Nonetheless, this time-varying default probability is helpful to demonstrate repercussions in the simplest possible setting.
} 
where $W_{s}^{*}$ is a standard Browninan motion such that

$$
d W_{s} \cdot d W_{s}^{*}=\rho d s, \text { for } \rho \in[-1,1]
$$

Finally, we consider the case that the probability of the retiree's mortality changes over time. We take into account the following time-varying mortality rate, $\nu_{t}$; for time $t \geq 0$,

$$
\text { Probability of }\left\{\tau_{M} \leq t\right\}=\int_{0}^{t} \nu_{s} d s \text {, }
$$

satisfying, for time $t \geq 0$,

$$
d \nu_{s}=\tilde{a} \nu_{s} d s+\tilde{b} \nu_{s} d \widetilde{W}_{s}, \quad \nu_{0}=\nu>0, \tilde{a}<0, \tilde{b}>0
$$

where $\widetilde{W}_{s}$ is a standard Browninan motion independent of $W_{s}$ and $W_{s}^{*} \cdot{ }^{20}$

\subsection{Bequest Motive}

We can confirm the result obtained previously (Friedman and Warshawsky, 1990; Brown, 2001; Johnson et al., 2004) that the retiree's voluntary annuity demand decreases with

${ }^{20}$ Letting $a=-\delta(\tilde{a}=-\nu)$, and $b=0(\tilde{b}=0)$, the time of default, $\tau$, (the time of death, $\left.\tau_{M}\right)$ follows a simple exponential distribution with intensity $\delta$ ( $\nu$, respectively) as the following:

$$
d \delta_{s}=-\delta \delta_{s} d s, \text { and } d \nu_{s}=-\nu \nu_{s} d s
$$

or equivalently,

$$
\delta_{s}=\delta e^{-\delta s}, \text { and } \nu_{s}=\nu e^{-\nu s} .
$$

Accordingly, the probabilities of default and death are derived as

$$
\begin{aligned}
& \text { Probaility of }\{\tau \leq t\}=\int_{0}^{t} \delta e^{-\delta s} d s=1-e^{-\delta t}, \\
& \text { Probability of }\left\{\tau_{M} \leq t\right\}=\int_{0}^{t} \nu e^{-\nu s} d s=1-e^{-\nu t},
\end{aligned}
$$

reducing the case with constant default intensity $\delta$ and constant mortality rate $\nu$. 
the bequest motive $\tilde{k}$ (Table 6 ). The implicit value of life annuity decreases as the credit rating of annuity providers decreases, regardless of $\tilde{k}$. An increase in $\tilde{k}$ decreases disposable annuity payments, and thereby decreases the value of annuity holdings. Instead, the retiree can increase the amount of wealth that they bequeath to her heirs.

\section{[Insert Table 6 here.]}

\subsection{Correlation between Stock Price and Annuity Default Event}

The implicit values of $A$-rated and $B$-rated life annuities vary with changes in the correlation $\rho$ between the risky asset price and default intensity $\delta$ of life annuity (Table 7 ). When insurer default risk is negligible, implicit values of life annuities are lower when $\rho=20 \%$ than when $\rho=-20 \%$ whereas when insurer default risk is significant, the implicit values of life annuities are higher when $\rho=20 \%$ than when $\rho=-20 \%$. The market risk can be partially spanned by the annuity market: if the positive correlation is concerned, the effectiveness of hedging with life annuities is reduced; whereas if the negative correlation is considered, the effectiveness of hedging with life annuities is increased. Thus the spanning of the market risk may be one of the most important factors when investing in the annuity market. However, the spanning is an order of magnitude smaller than the damage caused by insurer default. If retirees expect a very high insurer default risk, an investment in annuities is not optimal, even if the correlation is negative. The extremely low implicit value of $B$-rated life annuity is an accurate representation of how retirees perceive defaultable life annuities. 


\section{[Insert Table 7 here.]}

\subsection{Time-Varying Mortality Rates}

As the standard deviation on mortality rates $\tilde{b}$ increases, the implicit value of life annuity decreases for insurance providers that have good credit ratings such as $A a a, A a, A$ (Table 8). The advantage of a life annuity is that it hedges against uncertain life expectancy, but this advantage is offset by the uncertainty that is imposed by time variation in mortality rate. However, this result might not be the case if we included insurers that are more at risk of finding themselves in bankruptcy than are firms that have $A a a, A a$, and $A$ credit ratings. Indeed, the implicit value increases with the standard deviation for an insurer that has a bad credit rating such as $B$. Even though insurers are at imminent risk of default, annuity income that turns out to be defaultable still allows retirees to finance current and future consumption, and thereby to mitigate problems that result from fluctuations in mortality rates.

One can predict for sure what insurer default means to retirees by concluding that the voluntary annuity demand will shrink as the perceived risks of insurer default increases, regardless of temporal variation in mortality rates.

\section{[Insert Table 8 here.]}




\section{Conclusion}

We have derived an optimal portfolio choice for a retired person who has partially annuitized her wealth and is in danger of being caught up in insurer default. We have shown that the effects of default risk on the retiree's optimal asset allocation among the bond, stock, and annuity markets depend crucially on the level of default risk, risk aversion, and wealth. We hope that this paper lends itself to the study of both policy design and the basis of financial advice, especially for low-income retirees who are particularly vulnerable to annuity income risks.

Further work should increase the realism of the financial market to allow time variations and potential jumps in investment opportunity, and a comprehensively review of causes of insurer default. 


\section{Appendix: The Details of State Guaranty Associations}

A number of insurance companies have experienced substantial losses in economic downturns and a few of them even filed for bankruptcy. In the U.S. insurance companies such as Executive Life Insurance Co., First Capital Life Insurance Co., Monarch Life Insurance Co. failed after 1990, and the AIG Group underwent a liquidity crisis on 2008 and received a substantial government bailout of $\$ 85$ billion, which is the largest government bailout of a private company. In the United Kingdom National Assurance Co., English and American Insurance Co., Oaklife Assurance Co., and Equitable Life, the world's oldest life insurer, became insolvent in 1980s and 1990s. In the Netherlands, the ING Group received a 10 billion euro capital injection and Aegon a billion euro recapitalization fund during the 2008 global crisis.

However, in the U.S. and many other jurisdictions there are guarantee funds including state guaranty associations, so that individuals are possible to diversify default risks of insurance companies. While the maximum coverage limits vary from state to state, most states offer $\$ 100,000$ coverage in withdrawal and cash values for annuities. Actually, in case the claim of a policyholder exceeds the guaranty association coverage, the recovery amount of her excess claim depends highly on the liquidation ratio for the insolvency.

It is a common misunderstanding that policyholder recoveries in insurance liquidations are limited to guaranty association coverage limits or "caps." The truth is that whether a policyholder recovers all or most of her claim above guar- 
anty association caps depends significantly on whether regulatory intervention occurs before the failed company's assets have been substantially dissipated, and whether assets are effectively protected and marshaled in the company's receivership (Source: NOLHGA, 2011).

As the excerpt from the NOLHGA (2011) demonstrates, the recovery amount of the claim exceeding guaranty association limits depends crucially on the liquidation ratio for the insolvency of insurance company. Consider a policyholder who has a claim of $\$ 1$ million. Firstly, we suppose that there is no guaranty association protection. When the life annuity defaults and the liquidation ratio is $95 \%$, the policyholder recovers $\$ 950,000$ of the $\$ 1$ million claim. However, if the liquidation ratio is zero, then the policyholder recovers nothing (Figure 10).

\section{[Insert Figure 10 here.]}

For the next, we consider a case of guaranty association limit is $\$ 100,000$. Of course, the policyholder recovers all of the claim within $\$ 100,000$ when insurance company defaults. However, because she has a claim of $\$ 1$ million, the recovery amount of the excess claim is determined according to the liquidation ratio. If we assume that the liquidation ratio is $95 \%$, then the policyholder recovers $\$ 855,000$ of the excess claim of $\$ 900,000$. Hence, the amount of total recovery becomes $\$ 955,000$ ( $\$ 100,000$ plus $\$ 855,000$ ). However, when the liquidation ratio is $0 \%$, then the excess claim is not recovered at all (Figure 10).

Finally, we suppose that the guaranty association cap is $\$ 250,000$. If the liquidation ratio is $95 \%$, then the recovery amount of the excess claim for the policyholder is $\$ 712,500$. 
As a result, the total recovery for the policyholder is $\$ 962,000$ ( $\$ 250,000$ plus $\$ 712,500$ ). Note that even if the guaranty association cap is 2.5 times larger as we compared to the previous $\$ 100,000$, the total recovery increases a little, which is $\$ 7,500$. Furthermore, if the liquidation ratio is zero, then the policyholder bears a very large loss of $\$ 750,000$ (Figure 10). Accordingly, the excess claim is recovered by not the level of guaranty association limit, but the liquidation ratio.

According to the recent 2012 report of Moody's, the average "firm-wide" liquidation ratio for the 10 default resolutions was $53.4 \%$ in 2011 . Here, the firm-wide rate represents the weighted-average recovery rate across all of the issuer's debts in which the weights are the size of the debts. As we compared to $63.0 \%$ for 64 companies defaulted in 2010, the lower liquidation rate of $53.4 \%$ is induced by the ultimate resolutions for more than 1,000 default events in 2011. Hence, in the insolvencies claims on life annuities have been paid at a significant level. 


\section{References}

Babbel, D. F., and C. B. Merrill. 2007. Rational Decumulation. Working Paper.

Bayraktar E., M. A. Milevsky, S. D. Promislow, and V. R. Young. 2009. Valuation of Mortality Risk via the Instantaneous Sharpe Ratio: Applications to Life Annuities. Journal of Economic Dynamics and Control. 33 676-691.

Bensoussan, A., B.-G., Jang, and S. Park. 2016. Unemployment Risks and Optimal Retirement in an Incomplete Market. Operations Research. 64 1015-1032.

Blanchet-Scalliet C., N. E. Karoui, M. Jeanblanc, and L. Martellini. 2008. Optimal Investment Decisions with Time-Horizon is Uncertain. Journal of Mathematical Economics. 44 1100-1113.

Bodie, Z., R. C. Merton, and W. F. Samuelson. 1992. Labor Supply Flexibility and Portfolio Choice in a Life Cycle Model. Journal of Economic Dynamics and Control. 16 $427-449$.

Brown, J. R. 2001. Private Pensions, Mortality Risk, and the Decision to Annuitize. Journal of Public Economics. 82 29-62.

Chalmers, J., and J. Reuter. 2012. How Do Retirees Value Life Annuities? Evidence from Public Employees. Review of Financial Studies. 25 2601-2634.

Cocco, J. F., F. J. Gomes, and P. J. Meanhout. 2005. Consumption and Portfolio Choice 
over the Life-Cycle. Review of Financial Studies. 18 491-533.

Constantinides, G. M. 1986. Capital Market Equilibrium with Transaction Costs. Journal of Political Economy. 94 842-862.

Davidoff, T., J. Brown, and P. Diamond. 2005. Annuities and Individual Welfare. American Economic Review. 95 1573-1590.

Dybvig, P. H., and H. Liu. 2010. Lifetime Consumption and Investment: Retirement and Constrained Borrowing. Journal of Economic Theory. 145 885-907.

Farhi, E., and S. Panageas. 2007. Saving and Investing for Early Retirement: A theoretical Analysis. Journal of Financial Economics. 83 87-121.

Friedman, B. M., and M. J. Warshawsky. 1990. The Cost of Annuities: Implications for Saving Behavior and Bequests. Quarterly Journal of Economics. 105 135-154.

Heaton, J., and D. Lucas. 1997. Market Frictions, Savings Behavior, and Portfolio Choice. Macroeconomic Dynamics. 1 76-101.

Impavido, G., and I. Tower. 2009. How the Financial Crisis Affects Pensions and Insurance and Why the Impacts Matter. IMF Working Paper.

Inkmann, J., P. Lopes, and A. Michaelides. 2011. How Deep Is the Annuity Market Participation Puzzle? Review of Financial Studies. 24 279-319.

Jang, B. -G., H. K. Koo, H. Liu, and M. Loewenstein. 2007. Liquidity Premia and Trans- 
action Costs. Journal of Finance. 62 2329-2366.

Jang, B. -G., S. Park, and Y. Rhee. 2013. Optimal Retirement with Unemployment Risks. Journal of Banking ES Finance. 37 3585-3604.

Johnson, R., L. Burman, and D. Kobes. 2004. Annuitized Wealth at Older Ages: Evidence from the Health and Retirement Study. Urban Institute.

Koo, H. K. 1998. Consumption and Portfolio Selection with Labor Income: A Continuous Time Approach. Mathematical Finance. 8 49-65.

Liu, H., and M. Loewenstein. 2002. Optimal Portfolio Selection with Transaction Costs and Finite Horizons. Review of Financial Studies. 15 805-835.

Lopes, P., and A. Michaelides. 2007. Rare Events and Annuity Market Participation. Finance Research Letters. 4 82-91.

Merton, R. C. 1969. Lifetime Portfolio Selection under Uncertainty: The Continuous-Time Case. Review of Economics and Statistics. 51 247-257.

Merton, R. C. 1971. Optimal Consumption and Portfolio Rules in a Continuous-Time Model. Journal of Economic Theory. 3 373-413.

Milevsky, M. A., and V. R. Young. 2007. Annuitization and Asset Allocation. Journal of Economic Dynamics and Control. 31 3138-3177.

Mitchell, O., J. Poterba, M. Warshawsky, and J. Brown. 1999. New Evidence on the 
Money's Worth of Individual Annuities. American Economic Review. 89 1299-1318.

NOLHGA. 2011. Insurance Oversight and Legislative Proposals. National Organization of Life and Health Insurance Guaranty Associations Report.

Polkovnichenko, V. 2007. Life-Cycle Portfolio Choice with Additive Habit Formation Preferences and Uninsurable Labor Income Risk. Journal of Finance. 20 83-124.

Previtero, A. 2014. Stock Market Returns and Annuitization. Journal of Financial Economics. 113 202-214.

Richard, S. 1975. Optimal Consumption, Portfolio and Life Insurance Rules for an Uncertain Lived Individual in a Continuous Time Model. Journal of Financial Economics. 2 $187-203$.

Viceira, L. M., 2001. Optimal Portfolio Choice for Long-Horizon Investors with Nontradable Labor Income. Journal of Finance. 56 433-470.

Wang, C., N. Wang, and J. Yang. 2016. Optimal Consumption and Savings with Stochastic Income and Recursive Utility. Journal of Economic Theory. 165 292-331.

Yarri, M. E. 1965. Uncertain Lifetime, Life Insurance and the Theory of the Consumer. Review of Economic Studies. 32 137-150. 


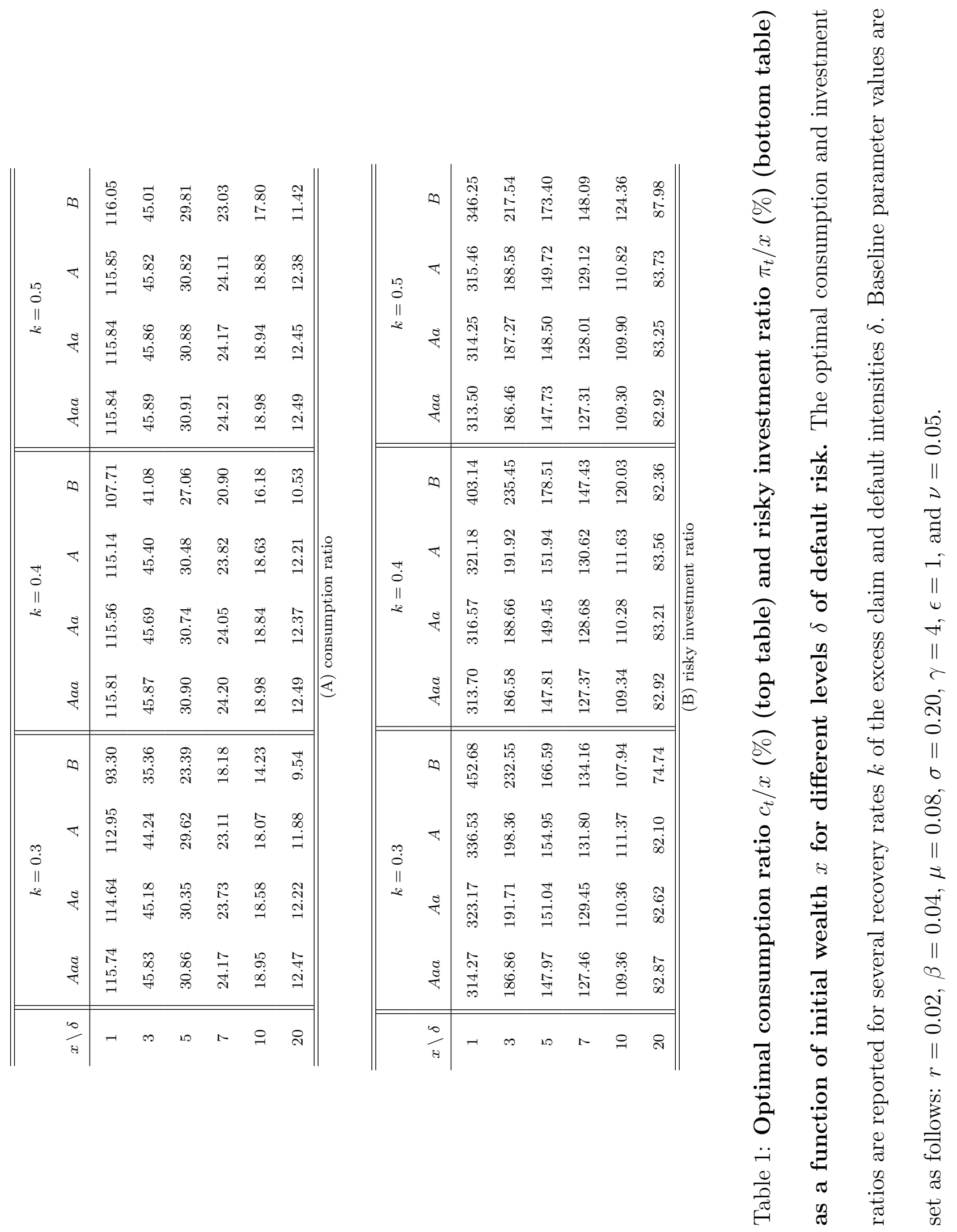




\begin{tabular}{c||cccc||cccc}
\hline \hline \multicolumn{1}{l||}{} & \multicolumn{5}{c||}{$\mu=0.06$} & \multicolumn{4}{c}{$\mu=0.07$} \\
\multicolumn{1}{c||}{ A $\backslash \delta$} & $A a a$ & $A a$ & $A$ & $B$ & $A a a$ & $A a$ & $A$ & $B$ \\
\hline 1 & 117.31 & 115.56 & 112.85 & 86.81 & 116.40 & 114.99 & 112.80 & 89.88 \\
3 & 45.63 & 44.59 & 43.13 & 32.27 & 45.66 & 44.83 & 43.64 & 33.71 \\
5 & 30.40 & 29.58 & 28.48 & 21.19 & 30.58 & 29.92 & 29.01 & 22.21 \\
7 & 23.61 & 22.92 & 22.02 & 16.42 & 23.85 & 23.29 & 22.53 & 17.22 \\
10 & 18.35 & 17.78 & 17.05 & 12.83 & 18.61 & 18.14 & 17.53 & 13.46 \\
20 & 11.85 & 11.48 & 11.03 & 8.59 & 12.13 & 11.82 & 11.42 & 9.02 \\
\hline \hline
\end{tabular}

(A) expected rate of return $\mu$

\begin{tabular}{c||cccc||cccc}
\hline \hline \multicolumn{1}{l||}{} & \multicolumn{5}{c||}{$\sigma=0.21$} & \multicolumn{5}{c}{$\sigma=0.22$} \\
\multicolumn{1}{c|}{ A $\backslash \delta$} & $A a a$ & $A a$ & $A$ & $B$ & $A a a$ & $A a$ & $A$ & $B$ \\
\hline 1 & 117.50 & 115.70 & 112.89 & 89.87 & 117.68 & 115.82 & 112.93 & 85.81 \\
3 & 45.63 & 44.56 & 43.05 & 33.71 & 45.64 & 44.54 & 42.97 & 31.80 \\
5 & 30.37 & 29.53 & 28.39 & 22.21 & 30.35 & 29.48 & 28.31 & 20.87 \\
7 & 23.58 & 22.86 & 21.93 & 17.22 & 23.55 & 22.81 & 21.85 & 16.17 \\
10 & 18.30 & 17.72 & 16.97 & 13.46 & 18.27 & 17.66 & 16.90 & 12.63 \\
20 & 11.80 & 11.42 & 10.96 & 9.02 & 11.76 & 11.37 & 10.91 & 8.46 \\
\hline \hline
\end{tabular}

(B) volatility $\sigma$

Table 2: Optimal consumption ratio $c_{t} / x(\%)$ as a function of initial wealth $x$ for changes in expected stock return $\mu$ and stock volatility $\sigma$. The relation between a retiree's optimal consumption choice and the investment opportunity is revealed in this table. Baseline parameter values are set as follows: $r=0.02, \beta=0.04, \gamma=4, \epsilon=1$, $\nu=0.05$, and $k=0.3$. 


\begin{tabular}{|c|c|c|c|c|c|c|c|c|}
\hline \multirow[b]{2}{*}{$x \backslash \delta$} & \multicolumn{4}{|c|}{$\mu=0.06$} & \multicolumn{4}{|c|}{$\mu=0.07$} \\
\hline & $A a a$ & $A a$ & $A$ & $B$ & $A a a$ & $A a$ & $A$ & $B$ \\
\hline 1 & 235.26 & 248.71 & 268.86 & 381.35 & 277.80 & 289.05 & 305.81 & 423.38 \\
\hline 3 & 138.15 & 144.80 & 153.14 & 172.56 & 164.13 & 169.95 & 177.59 & 205.63 \\
\hline 5 & 108.48 & 112.33 & 116.49 & 117.22 & 129.42 & 132.94 & 137.09 & 143.64 \\
\hline 7 & 92.82 & 95.10 & 97.15 & 91.96 & 111.11 & 113.29 & 115.57 & 114.05 \\
\hline 10 & 79.01 & 79.95 & 80.42 & 72.67 & 94.95 & 95.95 & 96.73 & 90.64 \\
\hline 20 & 58.84 & 58.29 & 57.34 & 49.83 & 71.33 & 70.92 & 70.16 & 62.17 \\
\hline
\end{tabular}

(A) expected rate of return $\mu$

\begin{tabular}{c||cccc||cccc}
\hline \hline \multicolumn{1}{l||}{} & \multicolumn{5}{c||}{$\sigma=0.21$} & \multicolumn{5}{c}{$\sigma=0.22$} \\
\multicolumn{1}{c||}{ Aaa } & $A a$ & $A$ & $B$ & $A a a$ & $A a$ & $A$ & $B$ \\
\hline 1 & 215.62 & 228.75 & 248.51 & 423.38 & 198.29 & 211.07 & 230.39 & 329.89 \\
3 & 126.48 & 132.92 & 140.96 & 205.63 & 116.20 & 122.43 & 130.16 & 144.97 \\
5 & 99.23 & 102.94 & 106.87 & 143.64 & 91.10 & 94.67 & 98.39 & 97.11 \\
7 & 84.85 & 87.03 & 88.93 & 114.05 & 77.86 & 79.93 & 81.69 & 75.83 \\
10 & 72.18 & 73.05 & 73.44 & 90.64 & 66.19 & 67.01 & 67.32 & 59.98 \\
20 & 53.66 & 53.13 & 52.19 & 62.17 & 49.14 & 48.61 & 47.70 & 41.24 \\
\hline \hline
\end{tabular}

(B) volatility $\sigma$

Table 3: Optimal risky investment ratio $\pi_{t} / x(\%)$ as a function of initial wealth $x$ for changes in expected stock return $\mu$ and stock volatility $\sigma$. The relation between a retiree's optimal portfolio choice and the investment opportunity is revealed in this table. Baseline parameter values are set as follows: $r=0.02, \beta=0.04, \gamma=4, \epsilon=1$, $\nu=0.05$, and $k=0.3$. 


\begin{tabular}{c||cccc||cccc}
\hline \hline \multicolumn{1}{l||}{} & \multicolumn{5}{c||}{$\mu=0.06$} & \multicolumn{4}{c}{$\mu=0.07$} \\
\multicolumn{1}{c|}{ Aaa } & $A a$ & $A$ & $B$ & Aaa & $A a$ & $A$ & $B$ \\
\hline 1 & 15.92 & 14.84 & 13.32 & 5.8013 & 14.84 & 13.96 & 12.75 & 5.56 \\
3 & 19.81 & 17.86 & 15.45 & 6.4035 & 18.61 & 17.06 & 15.10 & 5.89 \\
5 & 22.30 & 19.61 & 16.66 & 6.3582 & 20.90 & 18.86 & 16.43 & 6.16 \\
10 & 26.54 & 22.52 & 18.76 & 5.9268 & 24.72 & 21.85 & 18.66 & 6.78 \\
20 & 30.93 & 26.05 & 21.64 & 4.9828 & 29.08 & 25.40 & 21.50 & 7.67 \\
30 & 33.14 & 28.39 & 23.73 & 3.9411 & 31.75 & 27.69 & 23.50 & 8.36 \\
\hline \hline
\end{tabular}

(A) expected rate of return $\mu$

\begin{tabular}{|c|c|c|c|c|c|c|c|c|}
\hline \multirow[b]{2}{*}{$x \backslash \delta$} & \multicolumn{4}{|c|}{$\sigma=0.21$} & \multicolumn{4}{|c|}{$\sigma=0.22$} \\
\hline & Aaa & $A a$ & $A$ & $B$ & $A a a$ & $A a$ & $A$ & $B$ \\
\hline 1 & 16.18 & 15.01 & 13.42 & 5.58 & 16.37 & 15.15 & 13.51 & 5.74 \\
\hline 3 & 20.11 & 18.01 & 15.51 & 6.32 & 20.32 & 18.13 & 15.55 & 7.01 \\
\hline 5 & 22.48 & 19.74 & 16.69 & 6.26 & 22.70 & 19.85 & 16.71 & 6.30 \\
\hline 10 & 26.40 & 22.62 & 18.76 & 6.48 & 26.64 & 22.72 & 18.77 & 6.15 \\
\hline 20 & 30.85 & 26.15 & 21.65 & 7.97 & 31.10 & 26.24 & 21.65 & 8.28 \\
\hline 30 & 33.56 & 28.50 & 23.77 & 8.47 & 33.80 & 28.60 & 23.79 & 8.40 \\
\hline
\end{tabular}

(B) volatility $\sigma$

Table 4: Implicit value of life annuity as a function of initial wealth $x$ for changes in expected stock return $\mu$ and stock volatility $\sigma$. The table shows how the implicit value changes with the investment opportunity, for different levels of default intensity $\delta$. Baseline parameter values are set as follows: $r=0.02, \beta=0.04, \gamma=4, \epsilon=1, \nu=0.05$, and $k=0.3$. 


\begin{tabular}{|c|c|c|c|c|c|c|c|c|}
\hline \multirow[b]{2}{*}{$x \backslash \delta$} & \multicolumn{4}{|c|}{$\mu=0.06$} & \multicolumn{4}{|c|}{$\mu=0.07$} \\
\hline & $A a a$ & $A a$ & $A$ & $B$ & Aaa & $A a$ & $A$ & $B$ \\
\hline 1 & 5.81 & 62.33 & 134.14 & 625.32 & 4.32 & 47.28 & 103.95 & 529.97 \\
\hline 10 & 1.44 & 15.01 & 31.07 & 102.08 & 1.12 & 11.93 & 25.37 & 93.81 \\
\hline 20 & 0.92 & 9.53 & 19.75 & 70.62 & 0.73 & 7.76 & 16.50 & 64.99 \\
\hline 30 & 0.68 & 7.05 & 14.62 & 54.27 & 0.55 & 5.83 & 12.41 & 50.18 \\
\hline 40 & 0.53 & 5.59 & 11.61 & 44.20 & 0.44 & 4.68 & 9.97 & 41.07 \\
\hline 50 & 0.46 & 4.62 & 9.61 & 37.35 & 0.35 & 3.93 & 8.32 & 34.86 \\
\hline
\end{tabular}

(A) expected rate of return $\mu$

\begin{tabular}{c||cccc||cccc}
\hline \hline \multicolumn{1}{c||}{} & \multicolumn{5}{c||}{$\sigma=0.21$} & \multicolumn{5}{c}{$\sigma=0.22$} \\
\multicolumn{1}{c||}{ Aaa } & $A a$ & $A$ & $B$ & Aaa & $A a$ & $A$ & $B$ \\
\hline 1 & 3.42 & 37.88 & 84.59 & 463.56 & 3.73 & 41.15 & 91.37 & 487.4 \\
10 & 0.92 & 9.94 & 21.55 & 87.51 & 0.99 & 10.64 & 22.91 & 89.84 \\
20 & 0.61 & 6.58 & 14.25 & 60.63 & 0.65 & 7.00 & 15.05 & 62.24 \\
30 & 0.47 & 5.01 & 10.85 & 47.04 & 0.50 & 5.30 & 11.40 & 48.19 \\
40 & 0.36 & 4.06 & 8.79 & 38.66 & 0.40 & 4.27 & 9.21 & 39.54 \\
50 & 0.27 & 3.44 & 7.35 & 32.93 & 0.37 & 3.54 & 7.73 & 33.62 \\
\hline \hline
\end{tabular}

(B) volatility $\sigma$

Table 5: Certainty equivalent wealth gain to wealth ratio $\Delta(x) / x(\%)$ as a function of initial wealth $x$ for changes in expected stock return $\mu$ and stock volatility $\sigma$. The sensitivity of the certainty equivalent wealth gain to changes in the investment opportunity is reported in this table. Baseline parameter values are set as follows: $r=0.02$, $\beta=0.04, \gamma=4, \epsilon=1, \nu=0.05$, and $k=0.3$. 


\begin{tabular}{c||cccc||rccc}
\hline \hline \multicolumn{1}{l||}{} & \multicolumn{4}{c||}{$\tilde{k}=0.05$} & \multicolumn{5}{c}{$\tilde{k}=0.10$} \\
\multicolumn{1}{c|}{} & \multicolumn{1}{c||}{ Aaa } & $A a$ & $A$ & $B$ & $A a a$ & $A a$ & $A$ & $B$ \\
\hline 1 & 12.47 & 11.96 & 11.23 & 5.54 & 11.51 & 11.11 & 10.54 & 5.60 \\
3 & 15.12 & 14.32 & 13.22 & 5.94 & 13.60 & 13.01 & 12.19 & 5.79 \\
5 & 16.63 & 15.63 & 14.32 & 6.19 & 14.76 & 14.07 & 13.09 & 5.86 \\
10 & 19.14 & 17.83 & 16.17 & 6.70 & 16.71 & 15.86 & 14.65 & 6.56 \\
20 & 22.18 & 20.57 & 18.54 & 7.55 & 19.22 & 18.16 & 16.84 & 7.80 \\
30 & 24.13 & 22.42 & 20.21 & 8.23 & 20.97 & 19.84 & 18.44 & 8.21 \\
\hline \hline
\end{tabular}

Table 6: Implicit value of life annuity as a function of initial wealth $x$ for changes in the parameter $\tilde{k}$ which is a weight for bequest motive of a retiree. Baseline parameter values are set as follows: $r=0.02, \beta=0.04, \mu=0.08, \sigma=0.20, \gamma=4, \epsilon=1$, $\nu=0.05$, and $k=0.3$. 


\begin{tabular}{c||cc||cc}
\hline \hline & A-rated annuity provider & B-rated annuity provider \\
\cline { 2 - 5 }$x \backslash \rho$ & 0.2 & -0.2 & 0.2 & -0.2 \\
\hline 1 & 12.89 & 13.25 & 5.63 & 5.55 \\
5 & 17.83 & 18.19 & 6.22 & 6.35 \\
10 & 20.87 & 21.21 & 6.77 & 6.75 \\
15 & 22.89 & 23.24 & 7.28 & 7.10 \\
20 & 24.43 & 24.77 & 7.68 & 7.55 \\
\hline \hline
\end{tabular}

Table 7: Implicit value of life annuity as a function of initial wealth $x$ for changes in the correlation $\rho$ between stock price and annuity default event. Baseline parameter values are set as follows: $r=0.02, \beta=0.04, \mu=0.08, \sigma=0.20, \gamma=4, \epsilon=1$, $\nu=0.05, k=0.3$, and $b=0.05$. 


\begin{tabular}{c||cccc||cccc}
\hline \hline \multicolumn{1}{c||}{} & \multicolumn{5}{c||}{$\tilde{b}=0.01$} & \multicolumn{5}{c}{$\tilde{b}=0.1$} \\
\multicolumn{1}{c||}{ Aaa } & $A a$ & $A$ & $B$ & $A a a$ & $A a$ & $A$ & $B$ \\
\hline 1 & 13.51 & 12.89 & 12.59 & 5.63 & 11.70 & 11.36 & 10.85 & 5.76 \\
5 & 19.29 & 17.83 & 15.98 & 6.22 & 17.01 & 16.17 & 15.01 & 6.45 \\
10 & 22.96 & 20.87 & 18.34 & 6.77 & 20.42 & 19.17 & 17.51 & 6.91 \\
15 & 25.39 & 22.89 & 19.95 & 7.28 & 22.68 & 21.15 & 19.16 & 7.34 \\
20 & 27.19 & 24.43 & 21.22 & 7.68 & 24.38 & 22.66 & 20.38 & 7.71 \\
\hline \hline
\end{tabular}

Table 8: Implicit value of life annuity as a function of initial wealth $x$ for changes in the standard deviation $\tilde{b}$ on mortality rates $\nu$. Baseline parameter values are set as follows: $r=0.02, \beta=0.04, \mu=0.08, \sigma=0.20, \gamma=4, \epsilon=1, \nu=0.05$, and $k=0.3$. 


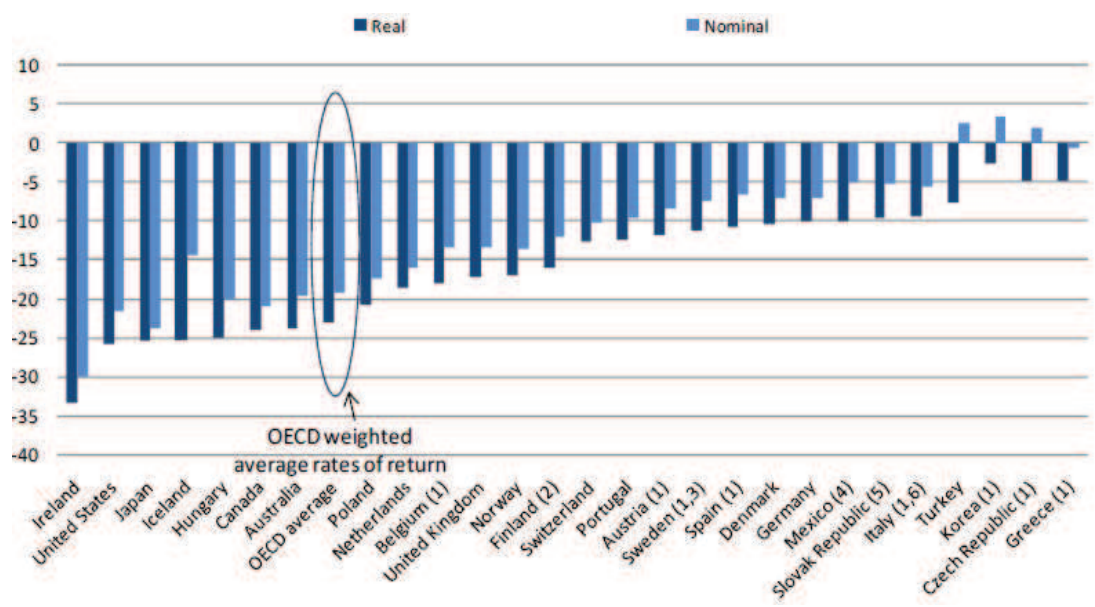

Figure 1: Pension fund returns in selected OECD countries (January-October 2008). Source: Impavido and Tower (2009).
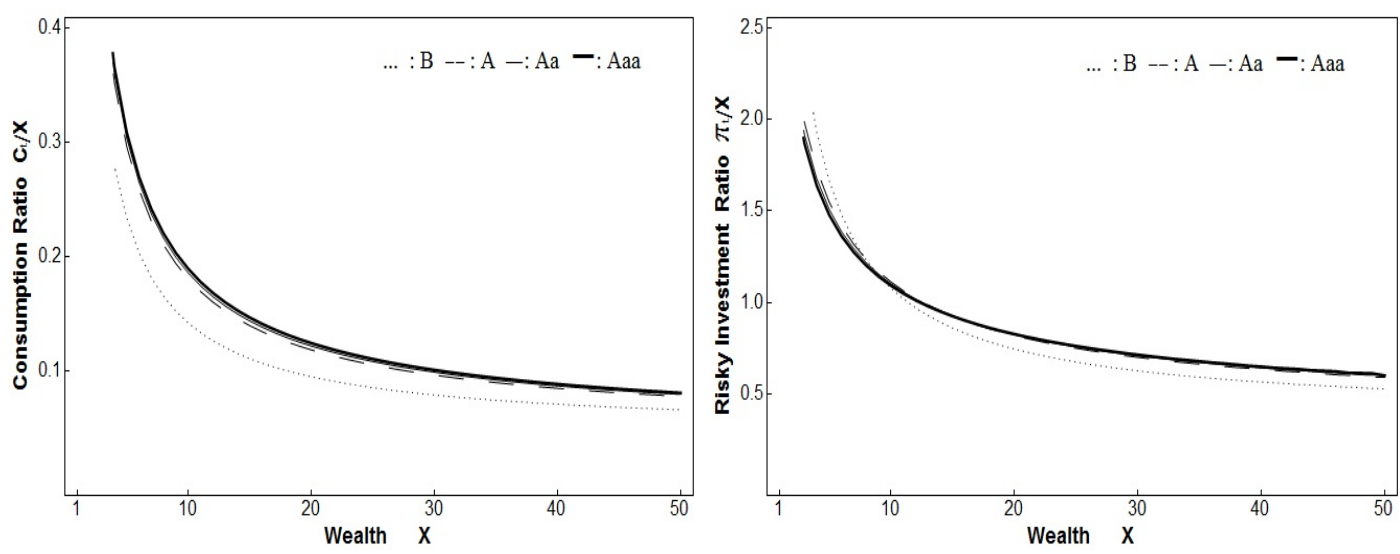

Figure 2: Optimal consumption ratio and risky investment ratio as a function of wealth $x$. This figure depicts the optimal consumption and investment ratios as a function of initial wealth for different levels of default risk when the recovery rate $k$ of the excess claim to $30 \%$. Baseline parameter values are set as follows: $r=0.02, \beta=0.04, \mu=0.08$, $\sigma=0.20, \gamma=4, \epsilon=1, \nu=0.05$, and $k=0.3$. 

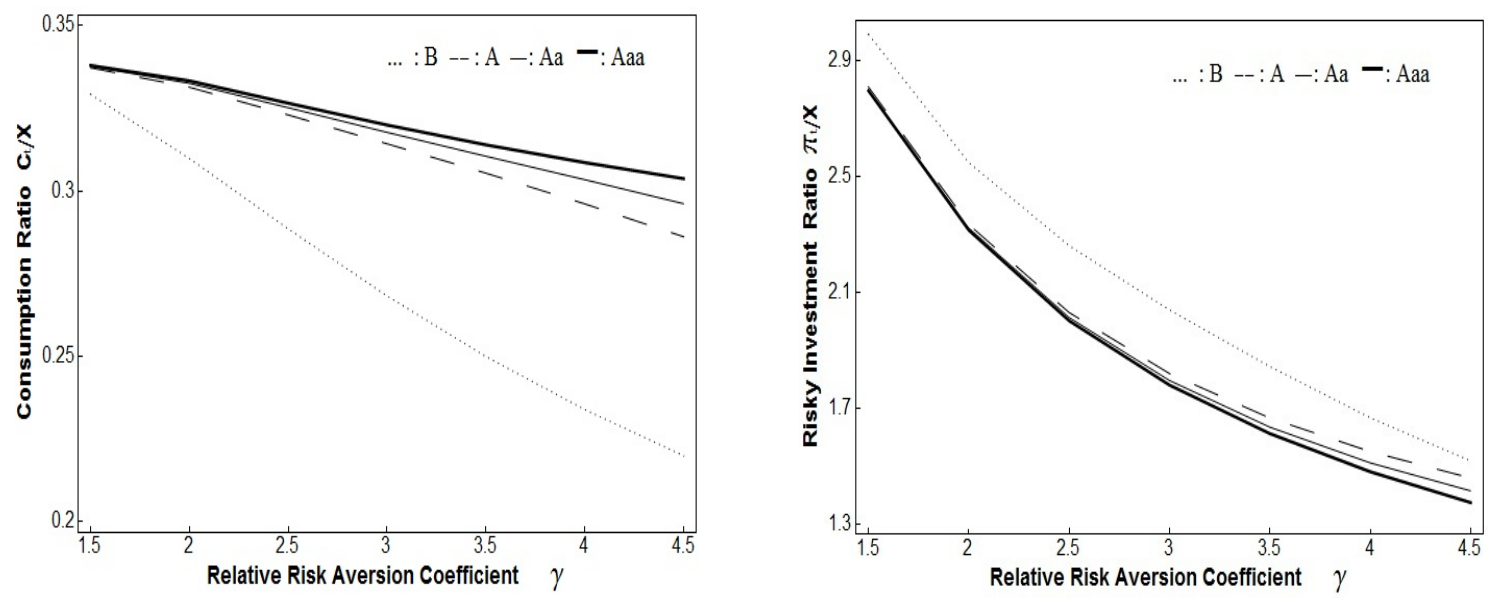

Figure 3: Optimal consumption ratio and risky investment ratio as a function of the coefficient $\gamma$ of risk aversion. Baseline parameter values are set as follows: $x=5$ (initial wealth), $r=0.02, \beta=0.04, \mu=0.08, \sigma=0.20, \epsilon=1, \nu=0.05$, and $k=0.3$.

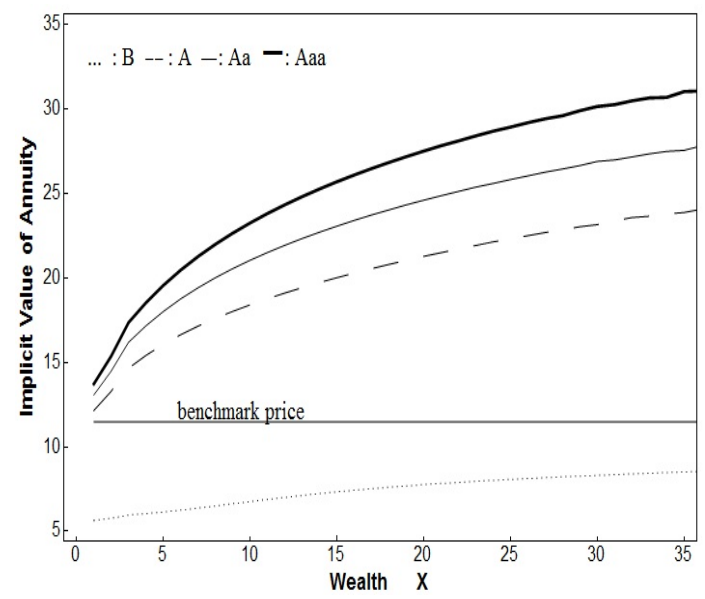

Figure 4: Implicit value of life annuity as a function of wealth $x$. Baseline parameter values are set as follows: $r=0.02, \beta=0.04, \mu=0.08, \sigma=0.20, \gamma=4, \epsilon=1, \nu=0.05$, and $k=0.3$. 

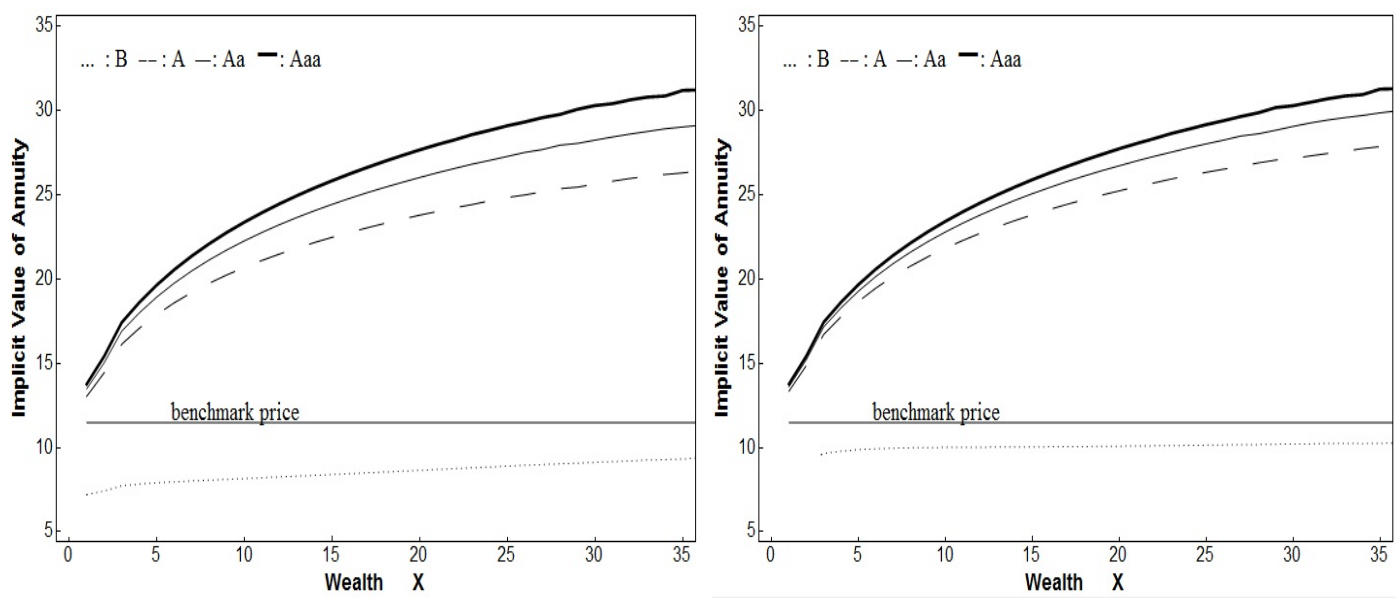

Figure 5: Implicit value of life annuity as a function of wealth $x$ (Left figure: $k=0.4$, Right figure: $k=0.5)$. Baseline parameter values are set as follows: $r=0.02$, $\beta=0.04, \mu=0.08, \sigma=0.20, \gamma=4, \epsilon=1$, and $\nu=0.05$.
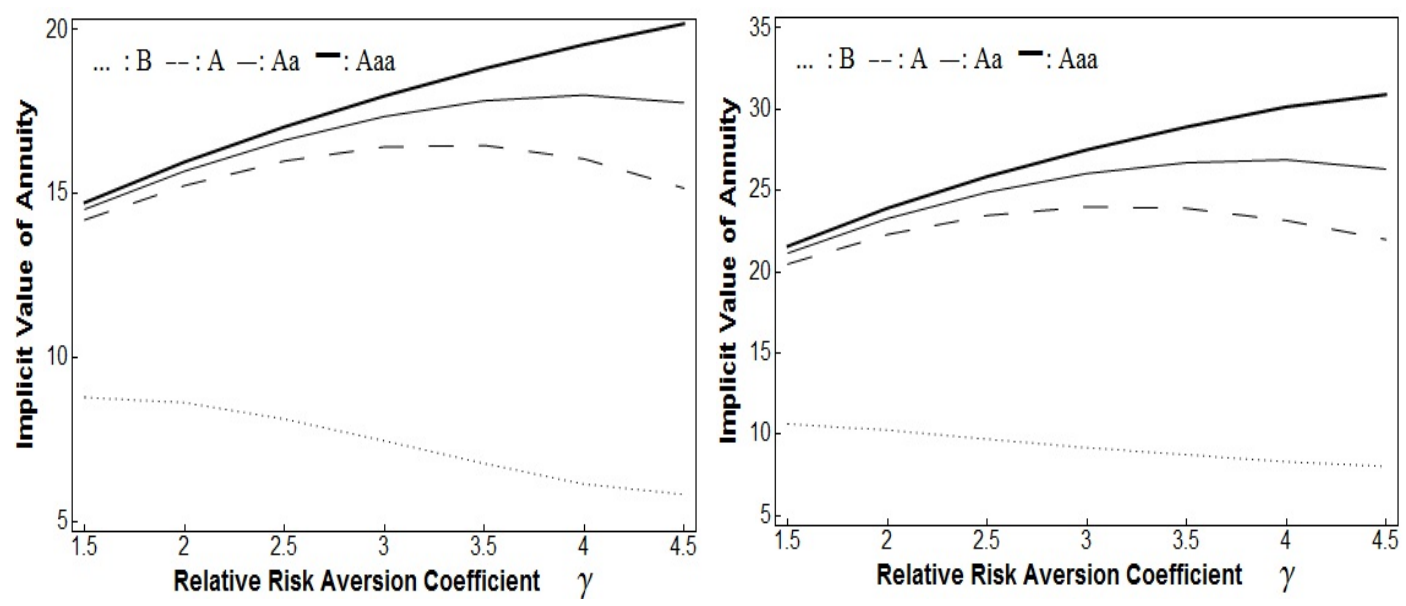

Figure 6: Implicit value of annuity as a function of the coefficient $\gamma$ of risk aversion (Left figure : $x=5$, Right figure: $x=30$ ). Baseline parameter values are set as follows: $x=5$ and $x=30, r=0.02, \beta=0.04, \mu=0.08, \sigma=0.20, \epsilon=1, \nu=0.05$, and $k=0.3$. 


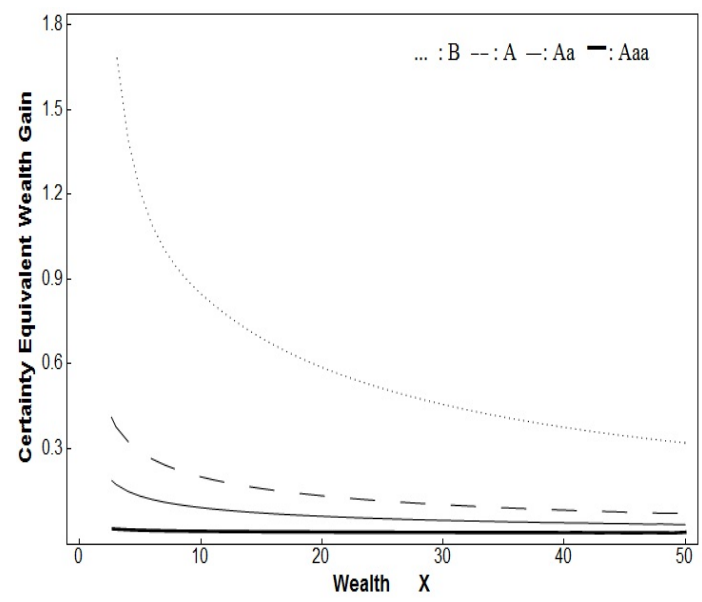

Figure 7: Certainty equivalent wealth gain to wealth ratio $\Delta(x) / x$ as a function of wealth $x$. Baseline parameter values are set as follows: $r=0.02, \beta=0.04, \mu=0.08$, $\sigma=0.20, \gamma=4, \epsilon=1, \nu=0.05$, and $k=0.3$.
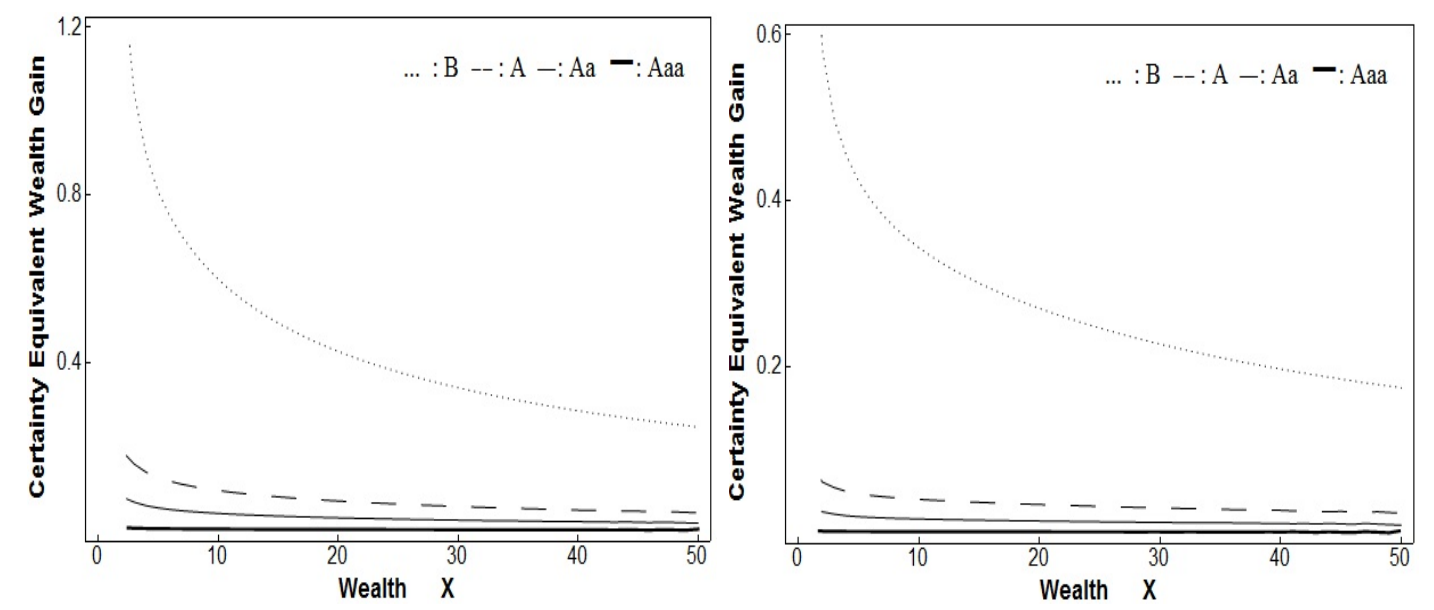

Figure 8: Certainty equivalent wealth gain to wealth ratio $\Delta(x) / x$ as a function of wealth $x$ (Left figure: $k=0.4$, Right figure: $k=0.5$. Baseline parameter values are set as follows: $r=0.02, \beta=0.04, \mu=0.08, \sigma=0.20, \gamma=4, \epsilon=1$, and $\nu=0.05$. 


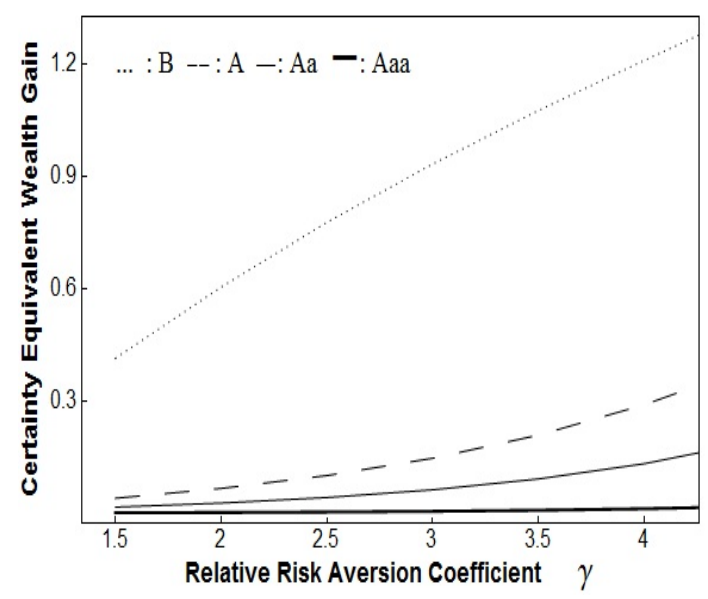

Figure 9: Certainty equivalent wealth gain to wealth ratio $\Delta(x) / x$ as a function of the coefficient $\gamma$ of risk aversion. Baseline parameter values are set as follows: $x=5$ (initial wealth), $r=0.02, \beta=0.04, \mu=0.08, \sigma=0.20, \epsilon=1, \nu=0.05$, and $k=0.3$. 

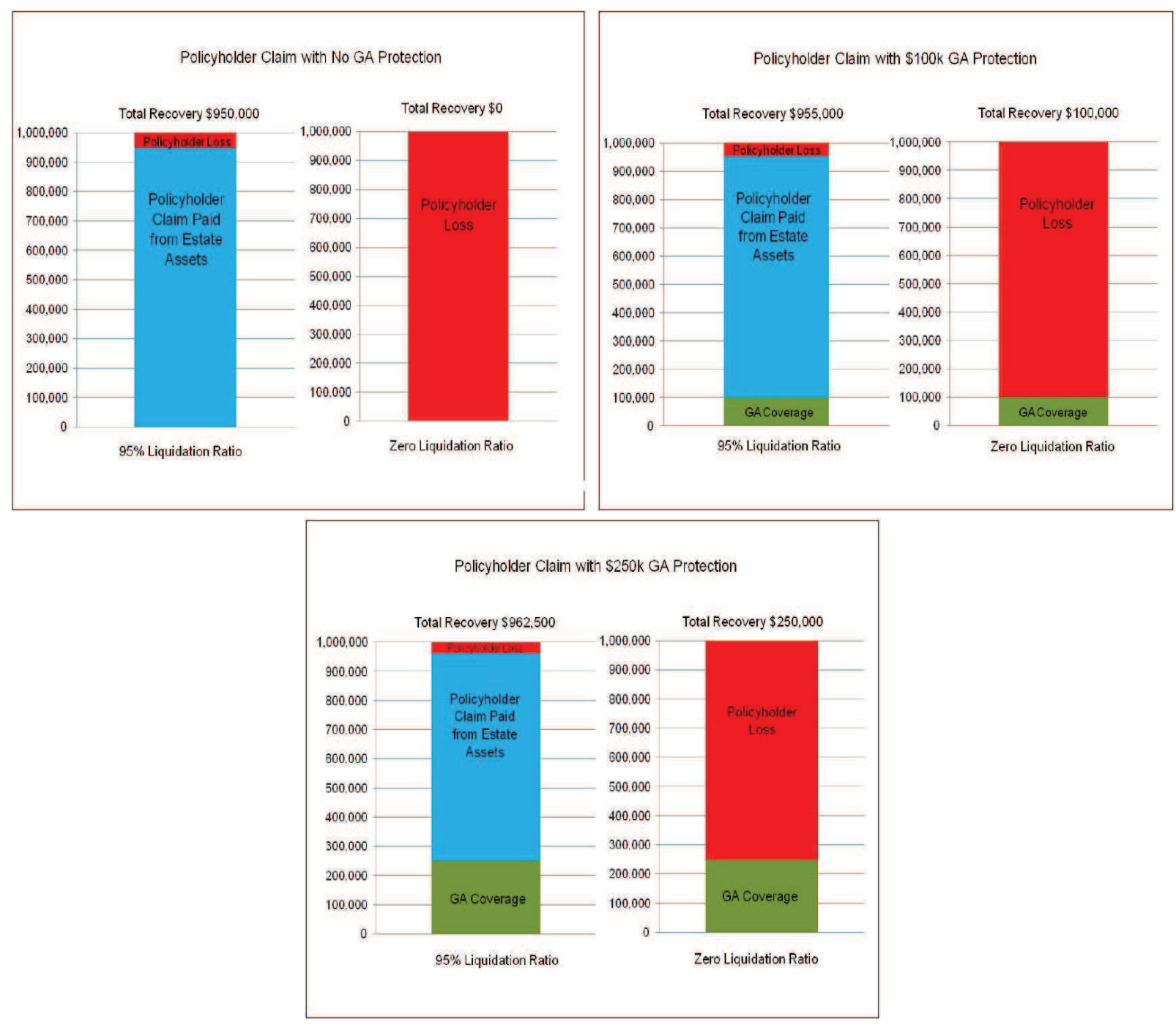

Figure 10: The recovery amount for the insurance insolvency. Source: NOLHGA (2011). 